\title{
Otoferlin Couples to Clathrin-Mediated Endocytosis in Mature Cochlear Inner Hair Cells
}

\author{
Susanne V. Duncker, ${ }^{1,2 \star}$ Christoph Franz, ${ }^{2 \star}$ Stephanie Kuhn, ${ }^{3,5 \star}$ Uwe Schulte, $, 4,8$ Dario Campanelli, ${ }^{2}$ Niels Brandt, ${ }^{5}$ \\ Bernhard Hirt, ${ }^{6}$ Bernd Fakler, ${ }^{4,9}$ Nikolaus Blin, ${ }^{7}$ Peter Ruth, ${ }^{1}$ Jutta Engel, ${ }^{5}$ Walter Marcotti, ${ }^{3}$ Ulrike Zimmermann, ${ }^{2}$ \\ and Marlies Knipper ${ }^{2}$ \\ ${ }^{1}$ Department of Pharmacology and Toxicology and ${ }^{2}$ Department of Otolaryngology, Tübingen Hearing Research Centre (THRC), Molecular Physiology of \\ Hearing, University of Tübingen, D-72076 Tübingen, Germany, ${ }^{3}$ Department of Biomedical Science, University of Sheffield, Sheffield S10 2TN, United \\ Kingdom, ${ }^{4}$ Institute of Physiology, University of Freiburg, D-79104 Freiburg, Germany, ${ }^{5}$ Institute of Physiology II and THRC, University of Tübingen, \\ D-72074 Tübingen, Germany, ${ }^{6}$ Institute of Anatomy, Department of Clinical Anatomy, University of Tübingen, D-72076 Tübingen, Germany, ${ }^{7}$ Institute \\ of Human Genetics, University of Tübingen, D-72074 Tübingen, Germany and ${ }^{8}$ Logopharm GmbH and ${ }^{9}$ Center for Biological Signaling Studies, 79104 \\ Freiburg, Germany
}

The encoding of auditory information with indefatigable precision requires efficient resupply of vesicles at inner hair cell (IHC) ribbon synapses. Otoferlin, a transmembrane protein responsible for deafness in DFNB9 families, has been postulated to act as a calcium sensor for exocytosis as well as to be involved in rapid vesicle replenishment of IHCs. However, the molecular basis of vesicle recycling in IHCs is largely unknown. In the present study, we used high-resolution liquid chromatography coupled with mass spectrometry to copurify otoferlin interaction partners in the mammalian cochlea. We identified multiple subunits of the adaptor protein complex AP-2 (CLAP), an essential component of clathrin-mediated endocytosis, as binding partners of otoferlin in rats and mice. The interaction between otoferlin and AP-2 was confirmed by coimmunoprecipitation. We also found that AP-2 interacts with myosin VI, another otoferlin binding partner important for clathrin-mediated endocytosis (CME). The expression of AP-2 in IHCs was verified by reverse transcription PCR. Confocal microscopy experiments revealed that the expression of AP-2 and its colocalization with otoferlin is confined to mature IHCs. When CME was inhibited by blocking dynamin action, real-time changes in membrane capacitance showed impaired synaptic vesicle replenishment in mature but not immature IHCs. We suggest that an otoferlin-AP-2 interaction drives Ca ${ }^{2+}-$ and stimulus-dependent compensating CME in mature IHCs.

\section{Introduction}

Dysfunction of otoferlin, a multi-C2 domain protein that acts as a calcium sensor in cochlear inner hair cells (IHCs), is responsible for auditory neuropathy/dyssynchrony (Varga et al., 2003) and

Received Dec. 13, 2012; revised April 17, 2013; accepted April 27, 2013.

Author contributions: S.V.D., C.F., U.S., B.F., N. Blin, P.R., J.E., W.M., U.Z., and M.K. designed research; S.V.D., C.F., S.K., U.S., D.C., N. Brandt, and B.H. performed research; S.V.D., C.F., S.K., U.S., B.F., W.M., U.Z., and M.K. analyzed data; S.V.D., C.F., S.K., U.S., N. Blin, J.E., W.M., U.Z., and M.K. wrote the paper.

This work was funded by the Marie Curie Research Training Network CavNET (MRTN-CT-2006 - 035367), the Deutsche Forschungsgemeinschaft (DFG-Kni-316-4-1), the Werner Reichardt Centre for Integrative Neuroscience (CIN) at the Eberhart Karls University of Tübingen. The CIN is an Excellence Cluster funded by the Deutsche Forschungsgemeinschaft within the framework of the Excellence Initiative (EXC 307), and the Sonderforschungsbereich SFB 894 (TP A8 to J.E.), a Baden-Württemberg research grant, a graduate program grant of the University of Tübingen, and the Wellcome Trust (088719 and 09189 to W.M.). W.M. is a Royal Society University Research Fellow. We thank K. Rohbock for excellent technical assistance and C. Müller and W. Bildl for their support of the AC-MS experiments.

*S.V.D., C.F., and S.K. contributed equally to this work.

The authors declare no competing financial interests.

This article is freely available online through the J Neurosci Author Open Choice option.

Correspondence should be addressed to Marlies Knipper, University of Tübingen, HNO-Klinik, Elfriede-Aulhorn-

Straße 5, 72076 Tübingen, Germany. E-mail: marlies.knipper@uni-tuebingen.de.

S. Kuhn's, N. Brandt's, and J. Engel's present address: Saarland University, Department of Biophysics, D-66421 Homburg/Saar, Germany.

N. Blin's present address: Wroclaw Medical University, Department of Genetics, 50-367 Wroclaw, Poland.

DOI:10.1523/JNEUROSCI.5689-12.2013

Copyright $\odot 2013$ the authors $\quad 0270-6474 / 13 / 339508-12 \$ 15.00 / 0$ various forms of autosomal recessive deafness DFNB9 (Yasunaga et al., 1999, 2000; Mirghomizadeh et al., 2002; Varga et al., 2003). Structural and functional similarities between otoferlin and synaptotagmin-1 (Syt1), including their $\mathrm{Ca}^{2+}$-dependent interaction with syntaxin-1, SNAP-25, and $\mathrm{Ca}_{\mathrm{V}} 1.3 \mathrm{Ca}^{2+}$ channels, suggested that otoferlin may act as a Syt1-like calcium sensor for fusion (Roux et al., 2006; Ramakrishnan et al., 2009; Baig et al., 2011). Consistent with this function, otoferlin regulates SNAREmediated membrane fusion in vitro (Johnson and Chapman, 2010) and is required for hair cell synaptic vesicle exocytosis (Roux et al., 2006). Despite that in otoferlin-deficient mice IHC exocytosis is nearly abolished (Roux et al., 2006), immature IHCs express several synaptotagmins (Beurg et al., 2010; Johnson et al., 2010) and do not seem to require otoferlin for transmitter release during early stages of development (Beurg et al., 2010). Also, in mature IHCs from a mouse model of human deafness DFNB9, which show a large reduction in the expression of otoferlin, the rapid replenishment of the readily releasable pool (RRP) was impaired, but not the ability to fuse synaptic vesicles (Pangršič et al., 2010). In addition, reduced synaptic vesicle replenishment of the secondary releasable pool (SRP) was observed in IHCs from hypothyroid rats, which show suppressed otoferlin expression (Johnson et al., 2010) due to the presence of immature-type cells in adult cochlea (Uziel et al., 1983). To explain the molecular 
mechanism underlying the role of otoferlin in both vesicle fusion and replenishment of the RRP, a mechanism involving clearance of vesicles from active release sites has recently been proposed (Pangršič et al., 2012). Clearance of vesicles from a readily retrievable vesicle pool at active release sites was shown to occur through a first wave of clathrin-mediated endocytosis (CME; Hua et al., 2011), which is a form of vesicle retrieval previously thought to be too slow for endocytosis in IHCs.

Using high-resolution liquid chromatography coupled with mass spectrometry (MS), we have identified subunits of the adaptor protein complex 2 (AP-2), which are crucial components of CME (for review, see Hirst and Robinson, 1998) and are otoferlin interaction partners. Coimmunoprecipitation assays, in combination with fluorescence microscopy, confirmed the interaction of otoferlin and AP-2 in mature IHCs. Measurements of realtime changes in membrane capacitance in immature and mature IHCs suggested that a clathrin/AP-2-dependent endocytosis process is crucial for sustained endocytosis in mature but not immature IHCs. We propose that otoferlin may recruit AP-2/CME only after hearing onset. This would explain how otoferlin, in addition to its function in RRP clearance (Pangršič et al., 2012), could contribute to the efficient $\mathrm{Ca}^{2+}$-regulated vesicle resupply (Griesinger et al., 2005; Levic et al., 2011), which is crucial to sustain the indefatigable properties of mature IHCs (Griesinger et al., 2005; Schnee et al., 2011).

\section{Materials and Methods}

Animals. Wistar rats and NMRI mice (Charles River) of either sex were used in this study. Hypothyroidism in rats was induced by treatment with methyl-mercapto-imidazol as described previously (Knipper et al., 2000; Friauf et al., 2008). Care and use of the animals as well as the experimental protocol were reviewed and approved by the animal welfare commissioner and the regional board for scientific animal experiments in Tübingen.

Tissue preparation. For immunohistochemistry, cochleae were isolated, dissected, cryosectioned at $10 \mu \mathrm{m}$, and mounted on SuperFrost ${ }^{*} /$ plus microscope slides at $-20^{\circ} \mathrm{C}$ as described previously (Knipper et al., 2000). For whole-mount immunohistochemistry, the temporal bone of mature mouse was dissected on ice and immediately fixed using Zamboni's fixative (Stefanini et al., 1967) containing picric acid by infusion through the round and oval window and incubated for $15 \mathrm{~min}$ on ice, followed by rinsing with PBS and dissection of cochlear turns. Cochlear whole mounts were transferred to slides and, for further immunohistochemical labeling, attached to the surface using Cell-Tak (BD Bioscience). For RNA and protein isolation, cochleae and brains were dissected, immediately frozen in liquid nitrogen, and stored at $-80^{\circ} \mathrm{C}$ before use.

Preparative affinity purification. Total cochleae (600) isolated from adult rat and mice were ground in liquid nitrogen and suspended in 10 $\mathrm{ml}$ lysis buffer (10 mm Tris-HCl, pH 7.4, 1 mm EDTA, 1 mm iodoacetamide and protease inhibitors) using a Dounce homogenizer (tight pestle). After centrifugation for $3 \mathrm{~min}$ at $800 \times g$, the pellet was resuspended in $10 \mathrm{ml}$ lysis buffer and centrifuged as before. The combined supernatants were then subjected to ultracentrifugation for $20 \mathrm{~min}$ at $150,000 \times$ $g$ and the resulting membrane pellet resuspended in $1 \mathrm{ml}$ lysis buffer $(8$ $\mathrm{mg}$ protein $/ \mathrm{ml}$ ), shock frozen in liquid nitrogen, and stored at $-80^{\circ} \mathrm{C}$. For solubilization, $2 \mathrm{mg}$ of membrane was resuspended in $2 \mathrm{ml} \mathrm{Com-}$ plexio Lyte (CL) detergent buffers (Logopharm; supplemented with protease inhibitors), CL-48 (rat) and CL-99 (mouse), incubated for $30 \mathrm{~min}$ at $4^{\circ} \mathrm{C}$ and ultracentrifuged at $150,000 \times g$ for $10 \mathrm{~min}$. Cleared solubilisates were incubated for $2 \mathrm{~h}$ with $25 \mu \mathrm{g}$ of immobilized anti-otoferlin antibody (Schug et al., 2006) or pre-immunization IgG as background control. After two rounds of washing with the respective solubilization buffer, bound proteins were eluted with $1 \times$ nonreducing Laemmli buffer. Aliquots of each step were taken and subjected to denaturing SDS-
PAGE/Western blot analysis to determine yields (self-cast mini-gels, Mini Protean 3 system; Bio-Rad; see Fig. 1B).

Mass spectrometric analysis. Samples obtained from affinity purifications were supplemented with $100 \mathrm{~mm}$ dithiothreitol, shortly run by SDS-PAGE gels, and the proteins visualized by silver staining. Gel lanes were then excised and in-gel digested with trypsin following a standard procedure (Pandey et al., 2000). Extracted peptides dissolved in $0.5 \%$ trifluoroacetic acid were loaded on a precolumn (C18 PepMap100, 5 $\mathrm{mm}$; Dionex) of an UltiMate 3000 HPLC (Dionex), and an aqueous organic gradient was then applied for elution and separation of peptides (75 mm column packed with C18 beads), which were directly electrosprayed into an LTQ-FT or Orbitrap-XL mass spectrometer (Thermo Scientific; ion source: Proxeon) as described in (Müller et al., 2010). Fragment (MS/MS) spectra were acquired after cycles of Fourier transform mass spectrum (FT-MS) full scans in data-dependent mode with dynamic exclusion (30 s) enabled. Extracted MS/MS spectra were searched against the UniProt knowledge base (mouse, rat, human, release 2012_05) using Mascot (version 2.3.01; Matrix Science). We allowed common variable modifications and one missed tryptic cleavage; peptide tolerance was $5 \mathrm{ppm}$ and MS/MS tolerance was $0.8 \mathrm{Da}$. Proteins that were identified by only one specific MS/MS spectrum or represented exogenous contaminations like keratins, trypsin, or immunoglobulins as well as proteins of mitochondrial and nuclear/ribosomal origin were not considered for further evaluation. Quantitative evaluation was performed using msInspect (Computational Proteomics Laboratory, Fred Hutchinson Cancer Research Center, Seattle, WA) as well as home-made software. First, $m / z$ signal intensities corresponding to an individual eluting peptide were integrated over time (i.e., across consecutive FT-MS spectra; Fig. $1 A$, step 7) to obtain its peak volume (PV) as a proportional measure of this peptide's abundance. Relative amounts of proteins were then calculated based on the PVs of selected protein (isoform)-specific peptides using the TopCorr method detailed in (Bildl et al., 2012). Accordingly, the enrichment of a protein was calculated as median of the respective peptide PV ratios in affinity capture sample (AC) versus IgG control (rPV). At least two peptides with assigned PVs of 100,000 volume units were required to ensure validity; if no PV could be assigned to a peptide in the corresponding IgG control, the detection limit of the spectrometer (3000 volume units) was used as a minimum estimate. Proteins were regarded as specifically (co)purified when their rPV values were $>10$ (Fig. 1C).

$m R N A$ isolation and reverse transcription-PCR. For reverse transcription (RT)-PCR analysis, mRNA from rat cochlea was isolated as described previously (Heidrych et al., 2008, 2009). For single cell RT-PCR analysis, mouse IHCs were collected with micropipettes (Knirsch et al., 2007) and frozen in liquid nitrogen. For RT-PCR analysis of brain tissue, mRNA was extracted using the Qiagen RNeasy Kit according to the manufacturer's instructions. cDNA synthesis was performed using the iScriptcDNA synthesis kit. For amplification of specific fragments of the different AP-2 subunits using RT-PCR, the following oligonucleotides were used $\left(5^{\prime}\right.$ to $\left.3^{\prime}\right)$ : Ap2a2, CCTTGGTCTGCCTATCGTGT and TGGGCTGGGACATTACTGAT (amplified length 232 bp); Ap2b1, CGCTCCTTCACCTACTCCTG and GTGAGTAAACGTCCCCGAAA (163 bp); Ap2m1, GCAAAATCAGCGAGGAGAAC and TTTCATCAGCTGTGCCTTTG (417 bp); and Ap2s1, CAGTTCGATGACGACGAGAA and CCAGGTCCAGTTCACAGACA (247 bp). As control, GAPDH was used and TCTACTGGCGTCTTCACCA and AGGAGACAACCTGGTCCTCAGT (550 bp). The resulting PCR products were analyzed on ethidium bromide agarose gels.

Protein isolation and analytical coimmunoprecipitation. Adult rat cochlear tissue and brains were used for Western blotting and analytical coimmunoprecipitation (co-IP). Protein isolation and co-IP was performed as described before (Schug et al., 2006; Heidrych et al., 2008, 2009). AP-2 was immunoprecipitated using $2.5 \mu \mathrm{g}$ of mouse anti-AP-2 antibody (BD Biosciences), whereas otoferlin was immunoprecipitated using 2.5-5 $\mu$ g polyclonal rabbit anti-otoferlin antibody (Schug et al., 2006). To confirm expression of the relevant proteins in cell lysates used for the co-IP, a control of $30 \mu \mathrm{g}$ of cell lysate was run in a separate lane (input). To ensure that the proteins were not producing false positive results by binding to the beads, we ran a bead control containing lysates 
plus beads without antibody. Electrophoresis and Western blotting for protein analysis was performed as described previously (Heidrych et al., 2008, 2009).

Immunohistochemistry. Immunohistochemistry on cochlear sections (Heidrych et al., 2009) and on whole-mount preparation (Engel et al., 2006) was performed as described before. Antibodies directed against AP-2 (mouse, adaptin $\alpha$; BD Biosciences), myosin VI (rabbit; Santa Cruz Biotechnology), otoferlin (rabbit, Schug et al., 2006; mouse, Abcam), and CtBP2 (rabbit; Cell Application) were used. Primary antibodies were detected with Cy3-conjugated (Jackson ImmunoResearch) or Alexa Fluor 488-conjugated secondary antibodies (Invitrogen). Sections were viewed using an Olympus BX61 microscope equipped with epifluorescence illumination. Images were acquired using a CCD camera and analyzed with cellSens software (Olympus Soft Imaging Solutions; OSIS). IHCs were imaged over a distance of $8 \mu \mathrm{m}$ in an image stack along the $z$-axis ( $z$-stack; $z$-stacks consisted of 30 layers with a $z$-increment of 0.276 $\mu \mathrm{m})$ and three-dimensionally deconvoluted using cellSens ADVMLE deconvolution algorithm (OSIS) to reach confocal-like resolution. Immunohistochemical staining was performed on at least three different sets of animals. Raw data for the analysis of relative intensity for single layers of the displayed $z$-stacks were derived using cellSens' line profiling tool (OSIS). Data for the intensity profiles shown in Figures 2 and 5 were normalized to the maximum of the relative intensity separately for each fluorochrome. Similarity of intensity profiles of fluorochromes was judged by Pearson correlation.

Electrophysiology. Apical coil mouse IHCs were studied in acutely dissected organs of Corti from postnatal day 4 to 7 (P4 to P7) and P11 to P17. Animals were killed by cervical dislocation in accordance with UK Home Office regulations. Cochleae were dissected as previously described (Johnson et al., 2010) in normal extracellular solution containing the following (in $\mathrm{mm}$ ): $135 \mathrm{NaCl}, 5.8 \mathrm{KCl}, 1.3 \mathrm{CaCl}_{2}, 0.9 \mathrm{MgCl}_{2}, 0.7$ $\mathrm{NaH}_{2} \mathrm{PO}_{4}, 5.6$ D-glucose, 10 HEPES-NaOH, 2 sodium pyruvate, amino acids, and vitamins ( $\mathrm{pH} 7.48$; osmolality $\sim 308 \mathrm{mmol} \mathrm{kg}^{-1}$ ). The pipette intracellular solution contained the following (in $\mathrm{mm}$ ): $106 \mathrm{Cs}$ glutamate, $20 \mathrm{CsCl}, 3 \mathrm{MgCl}_{2}$, 1 EGTA-CsOH, $5 \mathrm{Na}_{2} \mathrm{ATP}, 0.3 \mathrm{Na}_{2} \mathrm{GTP}, 5$ HEPES-CsOH, $10 \mathrm{Na}_{2}$-phosphocreatine (pH 7.3; osmolarity 294 mmol $\mathrm{kg}^{-1}$ ). Patch pipettes were coated with surfwax (Mr. Zog's Sex Wax) to minimize the fast patch pipette capacitance transient. All recordings were performed near body temperature $\left(35-37^{\circ} \mathrm{C}\right)$ and in the presence of $30 \mathrm{~mm}$ tetraethylammonium and $15 \mathrm{~mm} 4-\mathrm{AP}$ (Fluka) and linopirdine (80-100 $\mu \mathrm{M}$; Tocris Bioscience) to block the $\mathrm{K}^{+}$currents (Johnson et al., 2010). Data were recorded using an Optopatch amplifier (Cairn Research). Data acquisition was controlled by pClamp software using the Digidata 1322A board (Molecular Devices). Real-time changes in membrane capacitance $\left(\Delta C_{\mathrm{m}}\right)$ were measured using the Optopatch as previously described (Johnson et al., 2005, 2009, 2010). To examine the effect of dynamin on endocytosis, hair cells were superfused for at least 10 min before recording with the dynamin-1 and dynamin-2-specific blocker dynasore (dynasore hydrate; Sigma-Aldrich), which was also present throughout the recordings. Dynasore was dissolved in dimethylsulfoxide for stock solution (10 mM). For experiments, working solution containing $100 \mu \mathrm{M}$ dynasore in the extracellular solution was acutely prepared.

Statistical analysis. Statistical comparisons of means were made by a Student's two-tailed $t$ test for the time constant of endocytosis and by two-way ANOVA, followed by the Bonferroni post-test. Unless otherwise specified, mean values are quoted \pm SEM and $p<0.05$ indicates statistical significance.

\section{Results}

To identify potential interaction partners of otoferlin in the cochlea, we set up a functional proteomic screen combining immuno-affinity capture (AC) with tandem MS (Fig. 1A). Membranes prepared from rat and mouse cochleae were used as starting materials and tested first for conditions that effectively solubilize otoferlin protein. As shown in Figure $1 B$, two detergent buffers were previously applied to isolate membrane protein complexes (CL-48; Berkefeld et al., 2006) and tested for the iden- tification of interactions with cytoskeletal proteins (CL-99; Sharif-Naeini et al., 2009), which were used to quantitatively solubilize otoferlin from rat and mouse. These solubilisates were then subjected to affinity purification using an immobilized antiotoferlin antibody with pre-immune IgG as control (Schug et al., 2006) resulting in two AC datasets. Western blot analysis demonstrated that otoferlin ACs were effective (although not depleting) and specific with respect to IgG control as shown in Figure $1 B$, mouse cochlea/CL-99; lane E versus C. Eluates from both ACs were then subjected to high-resolution liquid chromatographyMS/MS (LC-MS/MS) and evaluated as previously described (Müller et al., 2010; Bildl et al., 2012). These MS analyses confirmed that otoferlin was effectively and specifically purified: 53 (rat) and 52 (mouse) otoferlin-specific peptides were identified, corresponding to relative primary sequence coverage of 41.5 and $40.6 \%$, respectively (data not shown), whereas no otoferlin peptides were detected in the IgG controls. To filter for biochemically robust interaction partners, proteins that were identified in both datasets (Table 1) were quantitatively evaluated using a label-free, PV-based method that offers an extended linear dynamic range (TopCorr method; Bildl et al., 2012; see Materials and Methods). Specificity and consistency of copurification for these proteins was determined by their enrichment in both ACs versus the corresponding IgG controls. Figure $1 C$ shows the result as a $2 \mathrm{D}$ rPV plot of the 45 proteins considered specifically purified $(\mathrm{rPV}>10)$ under both conditions (Table 1) together with otoferlin. Three of these proteins represented subunits of the AP-2 complex, namely $\alpha$ (AP2A2), $\beta$ (AP2B1) and $\mu$ (AP2M1). The AP-2 $\sigma$-subunit (AP2S1) was also identified but did not yield sufficient $\mathrm{m} / z$ signals for reliable quantification (data not shown).

We then analyzed the expression of AP-2 at the transcriptional level of mature animals using RT-PCR with RNA from whole rat cochlea (P20) or isolated mouse IHCs (P26) to confirm coexpression with otoferlin. The amplification products of $A p 2 a 2, A p 2 b 1$, $A p 2 m 1$, and Ap2s1 with the appropriate size were found in the mature cochlea (Fig. 1D). Moreover, the two larger subunits Ap2a2 and Ap2b1 could be amplified in isolated IHCs of the mature cochlea (Fig. 1E).

Using the anti-otoferlin antibody in combination with a monoclonal mouse anti-AP-2 antibody, high-resolution deconvolution fluorescence microscopy revealed a profound AP-2 labeling in mature IHCs (P19) that largely colocalized with otoferlin in the apical and in the basal pole of IHCs (Fig. 2A). Higher magnification (Fig. $2 B-D$ ) and relative pixel intensity profiles (Fig. $2 E-G$ ) derived from the fluorescent signals in Figure $2, B-D$, showed several coinciding intensity maxima of AP-2 and otoferlin staining on the supranuclear level (Fig. $2 B, E$, Pearson correlation coefficient, PCC $=0.562$ ), the basal pole region (Fig. $2 C, F, P C C=0.583)$, and in a vertical section from apex to base of an IHC (Fig. $2 D, G, P C C=0.694$ ). This localization profile was consistently found in mature IHCs without differences along the tonotopic axis in three biological replicates. In immature (P5) IHCs, prepared and immunostained as a whole-mount preparation at the same day and analyzed with fluorescence microscopy under similar conditions, otoferlin was expressed at a much lower level than in the mature IHC, confirming previous observations (Roux et al., 2006; Beurg et al., 2010). Also, AP-2 was found to be much less expressed at P5 (Fig. $2 H$ ) compared with mature (P19) IHCs.

Interestingly, in hypothyroid rat IHCs (P19), previously shown to lack otoferlin and to exhibit impaired replenishment of SRP (Johnson et al., 2010), expression of AP-2 was also not detectable (Fig. 2I, hypo). In control animals, AP-2-positive staining was found 
A

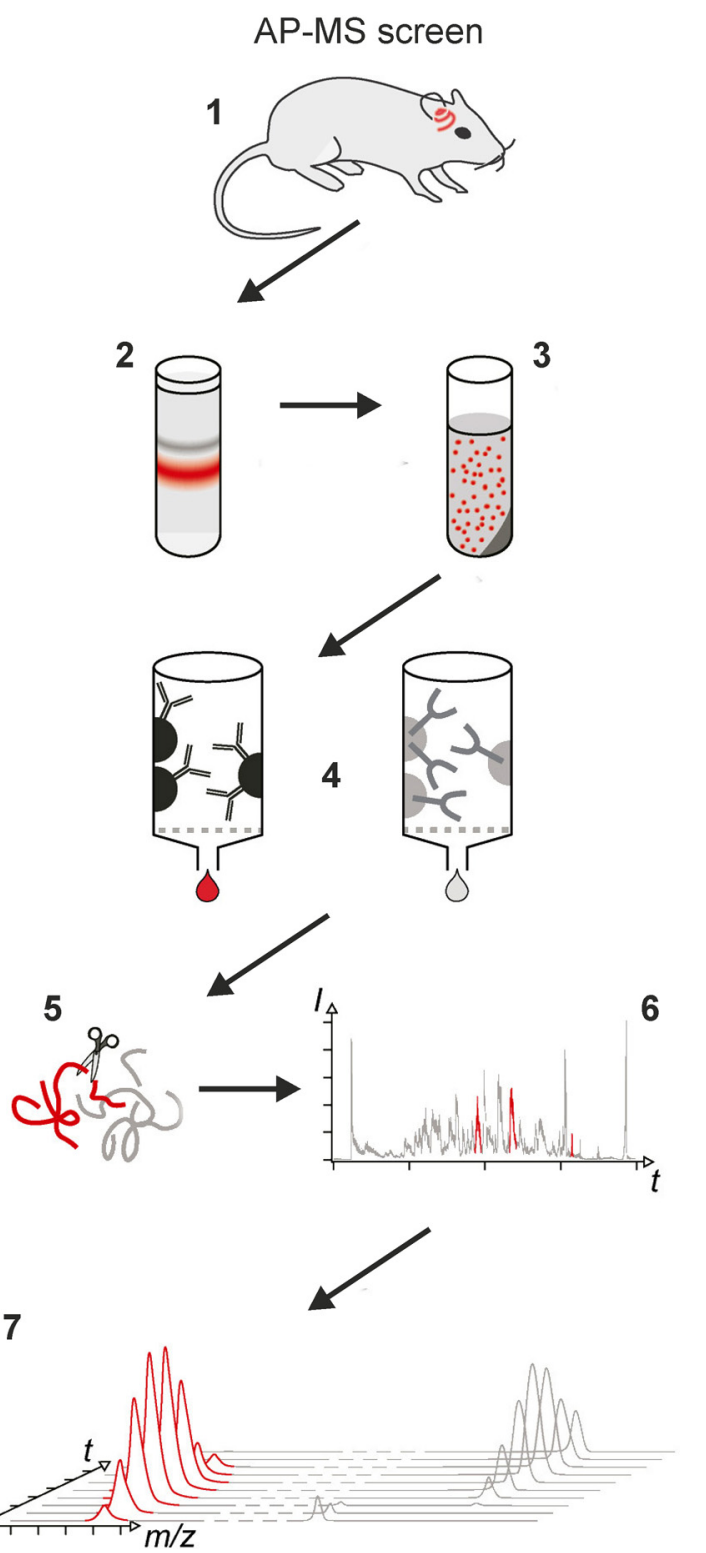

B

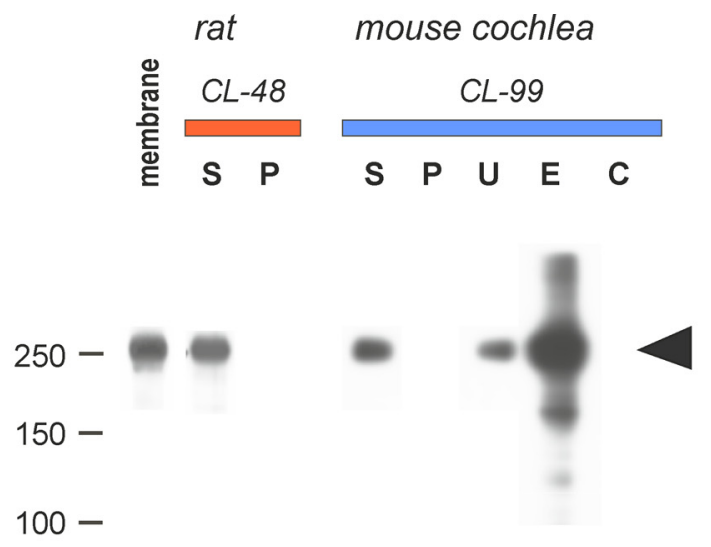

C

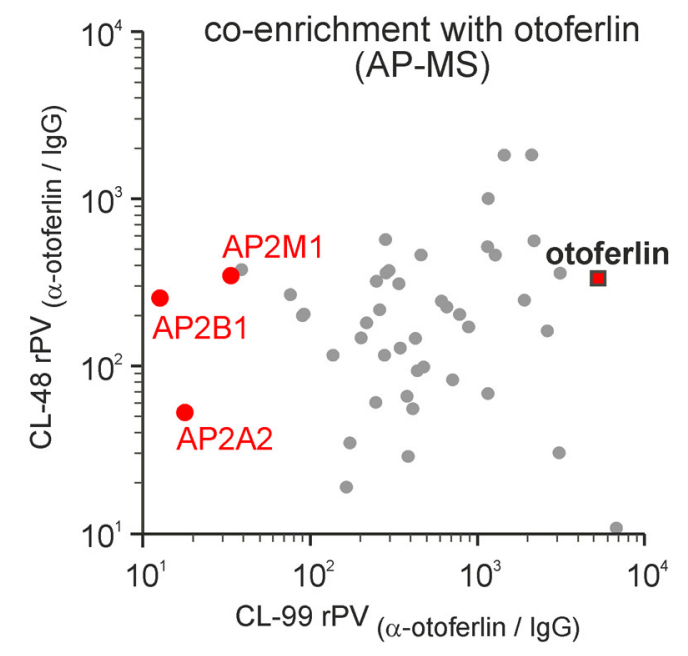

D

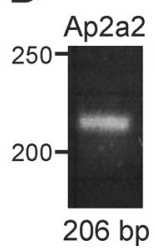

cochlea

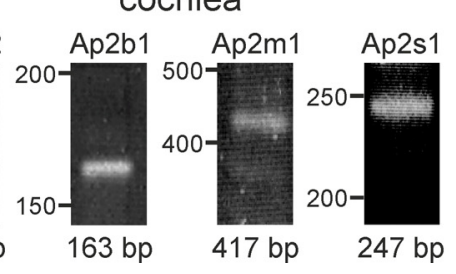

E $\quad$ IHC

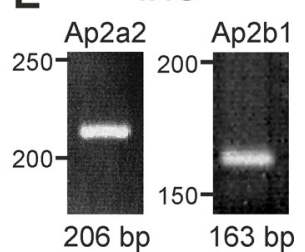

Figure 1. AC-MS screen of otoferlin-associated proteins in rat and mouse cochlea. A, lllustration of the AP-MS workflow starting with collection of rat/mouse cochleae (1), membrane preparation (2) and solubilization (3), affinity purification (4), tryptic digest (5), LC-MS/MS analysis (6), and integration of $\mathrm{m} / \mathrm{z}$ signals over time (PVs; 7) for quantitative evaluation; red color indicates the presence of otoferlin. $\boldsymbol{B}$, Western blot resolving aliquots of rat and mouse cochlea membrane, soluble $(S)$ and nonsoluble (P) fractions obtained with the indicated detergent buffers during solubilization, as well as unbound proteins (U) and eluates after AC with immobilized anti-otoferlin (E) and control lgG (C), respectively. Ten percent SDS-PAGE transferred to PVDF membrane, stained with anti-otoferlin/anti-rabbit-horseradish peroxidase and developed with $\mathrm{ECL}+$; the band corresponding to otoferlin is marked by an arrow. C, Proteins specifically affinity-captured from both rat (solubilized with CL-48; $y$-axis) and mouse (solubilized with CL-99; $x$-axis) cochlea, plotted by their relative abundance (rPV) in the respective purification with anti-otoferlin versus lgG control (for calculation of rPV values see Materials and Methods); $r$ PV values $>10$ indicate specific (co)-enrichment with otoferlin; dots represent individual proteins, subunits of the AP-2 complex are highlighted in red. D, E, RT-PCR analysis of AP-2. RT-PCR analysis of RNA samples from mature (P20) rat cochlea (D) and mature (P26) mouse IHCs (E). All four AP-2 subunits, Ap2a2, Ap2b1, Ap2m1, and Ap2s1, were found in the cochlea (D); in isolated IHCs, the two largest subunits Ap2a2, Ap2b1, were detected (E). Primer pairs each spanned at least one intron to distinguish between RNA and DNA signals. For more information see Materials and Methods.

in close association with the ribbon marker CtBP2. Unlike AP-2 under hypothyroid conditions, CtBP2 was expressed in the absence of TH (Fig. 2J). Specificity of the AP-2 antibody was demonstrated by omitting the primary AP-2 antibody (Fig. $2 K$ ).

Aiming to compare the relationship of AP-2 and otoferlin with the position of ribbons, respectively of otoferlin with AP-2, coimmunolabeling in cochlear whole-mount preparations was performed in adult mice. RIBEYE/CtBP2, a component of synaptic ribbons, was coimmunolabeled with either AP-2 (Fig. 3A) or otoferlin (Fig. $3 B$ ) and these profiles were compared with the protein distribution of AP-2 and otoferlin. The ribbon marker
CtBP2 is exclusively expressed at the IHC base (Fig. $3 A, B$, red), whereas AP-2 (Fig. $3 A$, green) and otoferlin (Fig. $3 B$, green) are distributed over the entire IHC cell body. The strong overlapping colabeling of otoferlin (red) and AP-2 (green) in the apical but also in the basal pole of IHCs (Fig. $3 C$ ) significantly differed from colabeling of AP-2 and CtBP2 (Fig. 3A1,A2) or otoferlin and CtBP2 (Fig. 3B1,B2). Taking into account the theoretical resolution of our microscope system in the horizontal plane $(211 \mathrm{~nm}$ for Cy3 and $192 \mathrm{~nm}$ for Alexa 488 (Zampini et al., 2010) and 46\% overlap as a criterion for colocalization due to spread of diffraction (for review, see Zampini et al., 2010), only a minor number 
Table 1. Proteins identified by MS-analysis of anti-otoferlin immuno-affinity capture from both rat (CL-48) and mouse (CL-99) cochlea membranes

\begin{tabular}{|c|c|c|c|c|c|c|c|}
\hline Accession & Protein & $\begin{array}{l}\text { CL-99 mouse } \\
\text { Specificity-ratio } \\
\text { AP-0tof_vs_lgG }\end{array}$ & $\begin{array}{l}\text { Identification } \\
\text { MS/MS matches }\end{array}$ & $\begin{array}{l}\text { Abundance } \\
\text { normalized OT }\end{array}$ & $\begin{array}{l}\text { CL-48 rat } \\
\text { Specificity-ratio } \\
\text { AP-0tof_vs_lgG }\end{array}$ & $\begin{array}{l}\text { Identification } \\
\text { MS/MS matches }\end{array}$ & $\begin{array}{l}\text { Abundance } \\
\text { normalized FT }\end{array}$ \\
\hline OTOF_RAT & $\underline{\text { Otoferlin }}$ & $\underline{5337.72}$ & 77 & 471850 & 337.79 & $\underline{76}$ & 104813 \\
\hline AT1A1_RAT & Sodium/potassium-transporting ATPase subunit $\alpha-1$ & 3122.83 & 50 & 1205148 & 30.40 & 96 & 1255648 \\
\hline AT1A3_RAT & Sodium/potassium-transporting ATPase subunit $\alpha-3$ & 1465.36 & 43 & 879001 & 1837.14 & 88 & 1033972 \\
\hline E41L2_MOUSE & Band 4.1-like protein 2 & 2140.55 & 84 & 1095333 & 1841.11 & 24 & 60963 \\
\hline AINX_RAT & $\alpha$-Internexin & 6867.19 & 50 & 685805 & 10.79 & 14 & 35343 \\
\hline NFM_RAT & Neurofilament medium polypeptide & 416.25 & 53 & 365494 & 55.75 & 10 & 25277 \\
\hline Z01_MOUSE & Tight junction protein Z0-1 & 77.16 & 54 & 316586 & 268.71 & 4 & 5551 \\
\hline NFH_MOUSE & Neurofilament heavy polypeptide & 204.23 & 43 & 778939 & 148.01 & 14 & 33070 \\
\hline SYVC_RAT & Valine-tRNA ligase & 2213.23 & 30 & 222839 & 564.34 & 20 & 34709 \\
\hline DYHC1_MOUSE & Cytoplasmic dynein 1 heavy chain 1 & 720.06 & 40 & 12029 & 83.15 & 5 & 259 \\
\hline MAP1A_RAT & Microtubule-associated protein $1 \mathrm{~A}$ & 1175.68 & 17 & 25327 & 1009.70 & 15 & 10000 \\
\hline AP2B1_RAT & AP-2 complex subunit $\boldsymbol{\beta}$ & 12.80 & 18 & 77577 & 256.35 & 5 & 8702 \\
\hline KTN1_MOUSE & Kinectin & 166.83 & 18 & 39455 & 18.94 & 5 & 3378 \\
\hline SYEP_MOUSE & Bifunctional glutamate/proline-tRNA ligase & 220.31 & 15 & 30906 & 182.44 & 6 & 2017 \\
\hline AT1B1_RAT & Sodium/potassium-transporting ATPase subunit $\beta-1$ & 2655.44 & 12 & 528908 & 163.22 & 9 & 960020 \\
\hline THOC2_MOUSE & THO complex subunit 2 & 350.05 & 19 & 32697 & 128.76 & 1 & 1228 \\
\hline SYDC_RAT & Aspartate-tRNA ligase, cytoplasmic & 663.92 & 15 & 40889 & 226.76 & 5 & 6012 \\
\hline AP2M1_RAT & AP-2 complex subunit $\mu$ & 34.01 & 13 & 71248 & 349.04 & 7 & 31463 \\
\hline G3P_RAT & Glyceraldehyde-3-phosphate dehydrogenase & 138.76 & 18 & 385951 & 116.67 & 1 & 5214 \\
\hline DHB12_RAT & Estradiol 17- $\beta$-dehydrogenase 12 & 792.80 & 13 & 226082 & 204.47 & 5 & 14065 \\
\hline TECR_RAT & Trans-2,3-enoyl-CoA reductase & 91.09 & 9 & 340731 & 201.07 & 9 & 109375 \\
\hline S4A11_MOUSE & Sodium bicarbonate transporter-like protein 11 & 285.68 & 7 & 22901 & 574.01 & 10 & 25618 \\
\hline G3BP1_MOUSE & Ras GTPase-activating protein-binding protein 1 & 1936.53 & 10 & 133366 & 249.11 & 6 & 12032 \\
\hline AT2A2_RAT & Sarcoplasmic/endoplasmic reticulum calcium ATPase 2 & 343.57 & 5 & 8408 & 312.43 & 11 & 21373 \\
\hline SYIC_MOUSE & Isoleucine-tRNA ligase, cytoplasmic & 897.52 & 12 & 19129 & 172.17 & 3 & 2509 \\
\hline AP2A2_RAT & AP-2 complex subunit $\alpha-2$ & 18.04 & 8 & 25002 & 52.97 & 6 & 5130 \\
\hline VDAC2_RAT & Voltage-dependent anion-selective channel protein 2 & 1296.57 & 8 & 234270 & 463.79 & 5 & 48350 \\
\hline RAB10_MOUSE & Ras-related protein Rab-10 0S = Mus musculus GN = Rab10 & 93.03 & 7 & 284745 & 205.67 & 6 & 56357 \\
\hline CPT1A_RAT & Carnitine 0-palmitoyltransferase 1, liver isoform & 252.10 & 6 & 18780 & 323.36 & 7 & 16289 \\
\hline ABD12_MOUSE & Monoacylglycerol lipase ABHD12 & 39.37 & 5 & 34497 & 379.34 & 7 & 25231 \\
\hline B3AT_RAT & Band 3 anion transport protein & 384.25 & 6 & 15168 & 66.29 & 5 & 2122 \\
\hline DHB11_RAT & Estradiol 17- $\beta$-dehydrogenase 11 & 617.70 & 7 & 63653 & 245.96 & 3 & 7379 \\
\hline S61A1_RAT & Protein transport protein Sec61 subunit $\alpha$ isoform 1 & 3168.89 & 6 & 144024 & 361.26 & 4 & 23034 \\
\hline S4A4_RAT & Electrogenic sodium bicarbonate cotransporter 1 & 281.99 & 5 & 7828 & 116.72 & 5 & 4033 \\
\hline GTR1_RAT & Solute carrier family 2, facilitated glucose transporter member 1 & 443.08 & 5 & 56109 & 94.27 & 4 & 26919 \\
\hline ALG2_MOUSE & $\alpha-1,3 / 1,6-$ mannosyltransferase ALG2 & 390.40 & 5 & 8839 & 28.93 & 4 & 8633 \\
\hline NSF_MOUSE & Vesicle-fusing ATPase & 483.27 & 6 & 11228 & 99.26 & 2 & 1225 \\
\hline VDAC3_RAT & Voltage-dependent anion-selective channel protein 3 & 1165.88 & 5 & 53167 & 519.99 & 3 & 36158 \\
\hline SYRC_RAT & Arginine-tRNA ligase, cytoplasmic & 431.76 & 3 & 5835 & 147.08 & 5 & 1974 \\
\hline THOC6_MOUSE & THO complex subunit 6 homolog & 1172.00 & 5 & 26504 & 68.87 & 2 & 1519 \\
\hline TMM33_MOUSE & Transmembrane protein 33 & 263.85 & 4 & 55563 & 218.08 & 1 & 9988 \\
\hline ZNT1_MOUSE & Zinc transporter 1 & 465.97 & 3 & 9477 & 463.94 & 2 & 9665 \\
\hline PTSS1_RAT & Phosphatidylserine synthase 1 & 299.75 & 2 & 19963 & 374.61 & 3 & 9647 \\
\hline SRP72_HUMAN & Signal recognition particle $72 \mathrm{kDa}$ protein & 288.12 & 2 & 4206 & 362.12 & 3 & 10462 \\
\hline NCKP1_RAT & Nck-associated protein 1 & 250.09 & 2 & 2138 & 60.87 & 1 & 526 \\
\hline MBB1A_RAT & Myb-binding protein $1 \mathrm{~A}$ & 175.19 & 2 & 2179 & 34.85 & 1 & 223 \\
\hline MYPO_RAT & Myelin protein PO & 16.21 & 43 & 37234494 & 2.61 & 68 & 10627302 \\
\hline PLEC_RAT & Plectin & 33.62 & 102 & 51673 & 0.02 & 2 & 1297 \\
\hline TBB5_MOUSE & Tubulin $\beta-5$ chain & 229.06 & 78 & 2449670 & 2.44 & 18 & 133357 \\
\hline CN37_RAT & $2^{\prime}, 3^{\prime}$-cyclic-nucleotide $3^{\prime}$-phosphodiesterase & 23.19 & 37 & 1789388 & 3.25 & 37 & 423459 \\
\hline NFL_RAT & Neurofilament light polypeptide & 617.59 & 44 & 1387637 & 3.47 & 21 & 90778 \\
\hline MBP_RAT & Myelin basic protein & 16.88 & 43 & 10126599 & 2.94 & 9 & 326297 \\
\hline HSP7C_RAT & Heat shock cognate $71 \mathrm{kDa}$ protein & 90.86 & 36 & 489906 & 7.47 & 8 & 29964 \\
\hline COCH_MOUSE & Cochlin & 40.67 & 24 & 241722 & 1.24 & 13 & 57796 \\
\hline CKAP4_MOUSE & Cytoskeleton-associated protein 4 & 28.46 & 24 & 206725 & 2.56 & 5 & 12684 \\
\hline MY06_MOUSE & Unconventional myosin-VI & 13.15 & 25 & 84374 & 0.11 & 2 & 2127 \\
\hline MYPR_MOUSE & Myelin proteolipid protein & 14.54 & 12 & 1413421 & 2.98 & 11 & 251283 \\
\hline HHATL_MOUSE & Protein-cysteine N-palmitoyltransferase HHAT-like protein & 2549.21 & 11 & 207284 & 4.96 & 12 & 90049 \\
\hline S12A2_MOUSE & Solute carrier family 12 member 2 & 454.19 & 13 & 33522 & 2.75 & 5 & 2656 \\
\hline MY01C_RAT & Unconventional myosin-lc & 398.84 & 6 & 3033 & 0.29 & 2 & 2183 \\
\hline S27A1_RAT & Long-chain fatty acid transport protein 1 & 0.00 & 5 & 8032 & 223.58 & 2 & 2935 \\
\hline EAA1_RAT & Excitatory amino acid transporter 1 & 0.00 & 2 & 208 & 4.91 & 3 & 13989 \\
\hline UIF_RAT & UAP56-interacting factor & 0.00 & 2 & 1783 & 97.93 & 1 & 3176 \\
\hline
\end{tabular}

Columns (left to right): database entry, protein name, purification specificity by the respective protein ratio (rPV, see Materials and Methods), identification by the number of database-matched MS/MS spectra and estimated molecular abundance based on the abundance ${ }_{\text {norm }}$ score (calculated as the sum of PVs divided by the number of MS-accessible amino acids of the respective protein; Müller et al., 2010 ). Proteins with specificity ratios $>10$ (bold) were displayed in Fig. 1C. 
otoferlin
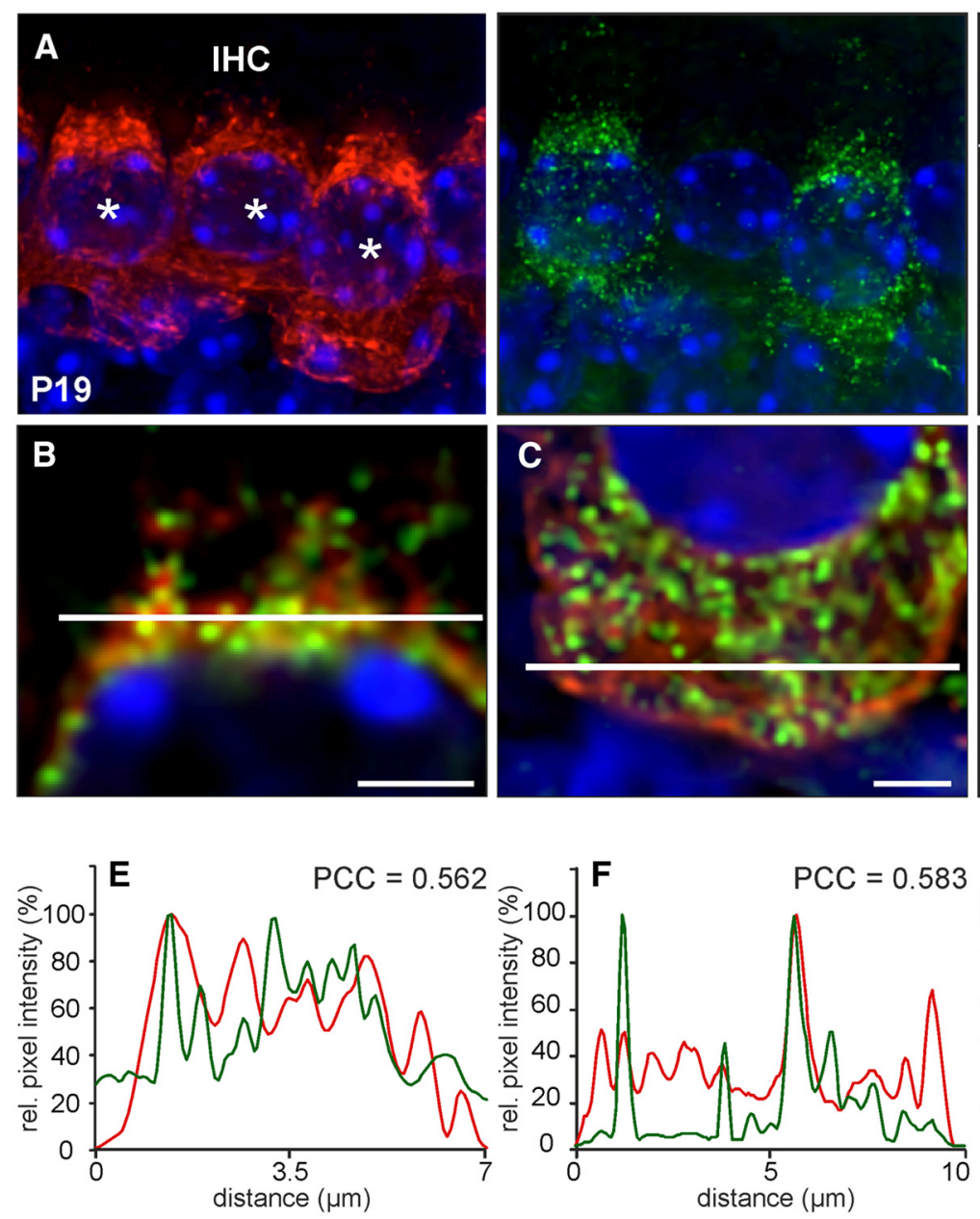

otoferlin
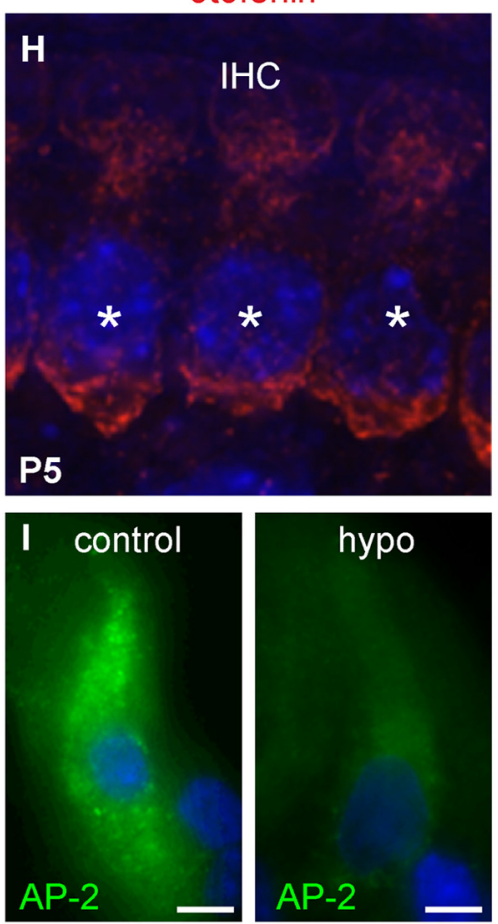

AP-2
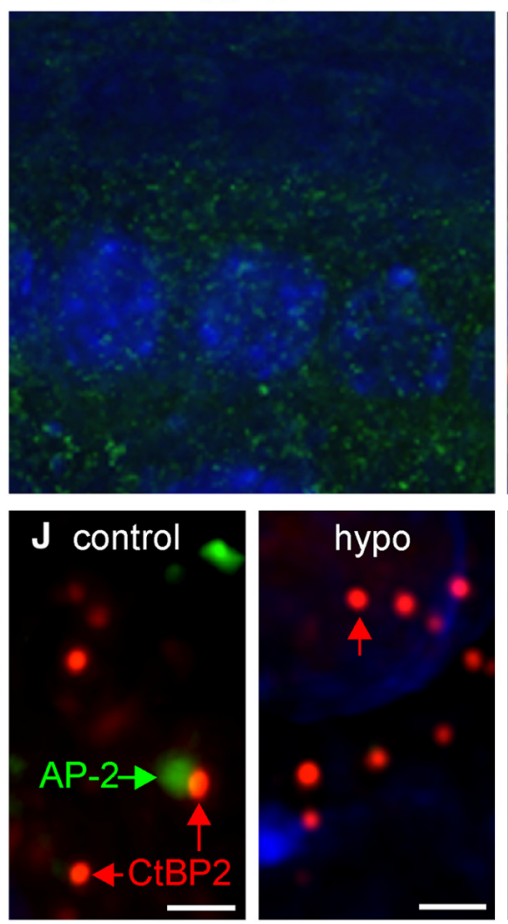

merge

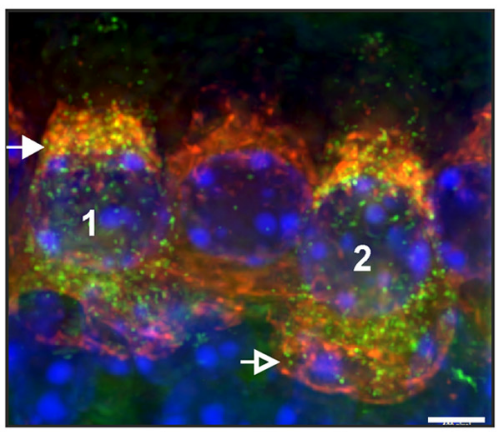

D
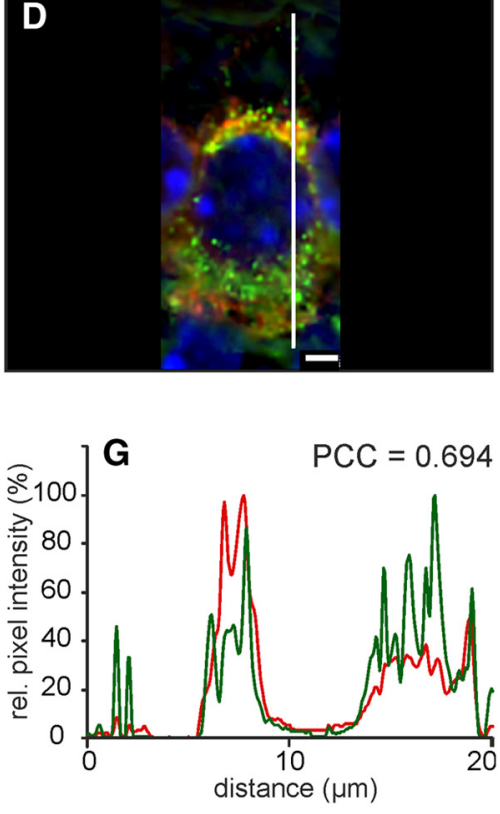

merge
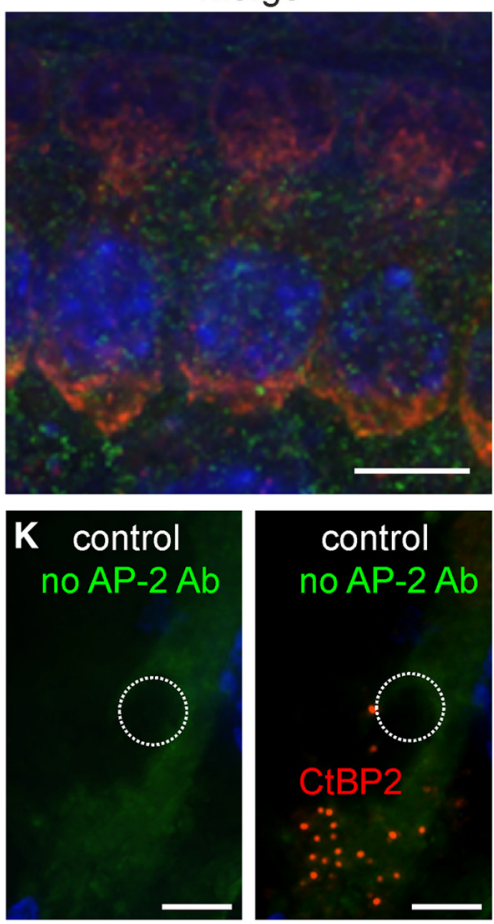

Figure 2. AP-2 protein expression in mature, immature, and hypothyroid rat cochlear IHCs. A, 0toferlin (red) and AP-2 (green) expression in mature (P19) mouse IHCs. AP-2 expression was found ubiquitously throughout the cytosol, whereas strong labeling of otoferlin was found predominantly at the supranuclear level (merge, closed arrow) and to a much lesser (Figure legend continues.) 

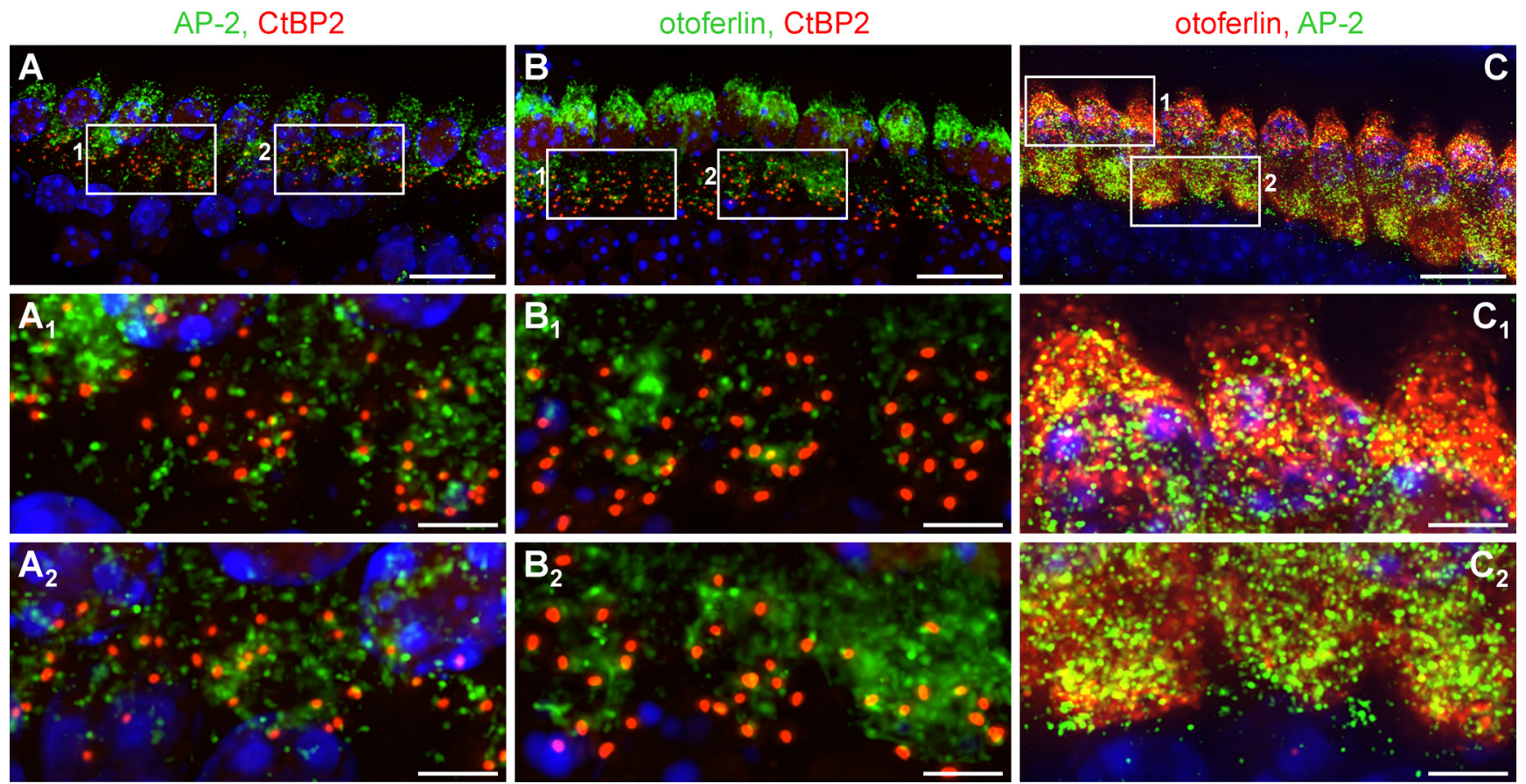

Figure 3. Comparison of the protein localization of AP-2 and otoferlin with the ribbon marker CtBP2.A-C, Whole-mount preparations of mice IHCs (P18) coimmunolabeled with AP-2 and CtBP2 $(\boldsymbol{A})$, otoferlin and $\mathrm{CtBP2}(\boldsymbol{B})$, or otoferlin and AP-2 (C). AP-2 $(\boldsymbol{A} 1, \mathbf{A} 2)$ and otoferlin $(\boldsymbol{B} 1, \boldsymbol{B} 2)$ showed only minor colocalization with CtBP2 at the basal pole of IHCs as demonstrated in two examples each. In contrast, otoferlin and AP-2 largely colocalized in the apical (C1) and in the basal pole (C2) of IHCs. Cell nuclei were counterstained with DAPI. Scale bars: (in A-C) $20 \mu \mathrm{m}$; (in A1,A2-C1,C2) $5 \mu \mathrm{m}$.

of ribbons fulfills the criteria of overlap for both otoferlin/CtBP2 and AP-2/CtBP2 as shown in two examples (Fig. 3A1,A2,B1,B2). This underlines a close positional overlap of otoferlin with AP-2 (Fig. 3C), and partial overlap of these proteins with CtBP2.

The interaction of otoferlin with AP-2 complex subunits in brain (Fig. 4A) and cochlear tissue (Fig. 4B) was confirmed using analytical co-IPs with a polyclonal rabbit anti-otoferlin antibody and a monoclonal mouse anti- $\alpha$-adaptin antibody. In Western blot analysis, both antibodies detected otoferlin (Fig. $4 A$, lane 1, input, $B$, lane 1 , input) and AP-2 polypeptides ( $\alpha-1$ and $\alpha$-2, also known as $\alpha$-adaptin $A$ and $\alpha$-adaptin C; Fig. $4 A$, lane 3, input, $B$, lane 2 , input) in brain and cochlear lysates, respectively. The detection of a 230 and $240 \mathrm{kDa}$ otoferlin double band in cochlear tissue is in accordance with (Yasunaga et al., 2000), who described that OTOF encodes multiple long and short isoforms. Also, Schug et al. (2006) described an otoferlin double band (230 and $240 \mathrm{kDa}$ ) in cochlear tissue and only the $230 \mathrm{kDa}$ polypeptide in rat brain. The $\alpha$-adaptin antibody recognized a 105 and a 112

\footnotetext{
(Figure legend continued.) extent at the base of IHCS (merge, open arrow). Images display maximum intensity projections of all layers of a $z$-stack. Cell nuclei were counterstained with DAPI. Scale bar: $10 \mu \mathrm{m}$. $\boldsymbol{B}-\boldsymbol{D}$, To better display colabeling, merged images are shown with higher magnifications of single layers out of the deconvoluted $z$-stack in $B$ from cell $1(A$, merge) and $(\boldsymbol{C}, \boldsymbol{D})$ from cell 2 ( $\boldsymbol{A}$, merge). Scale bars: (in $\boldsymbol{B}) 5 \mu \mathrm{m}$; (in $\boldsymbol{C}, \boldsymbol{D}) 2 \mu \mathrm{m}$. $\boldsymbol{E}-\boldsymbol{G}$, Normalized intensity profiles are drawn from the white lines in $(\boldsymbol{B}-\boldsymbol{D})$ and show the relative pixel intensity along the line in regards to the distance and fluorescence wave length (red, Cy3; green, Alexa 488). Colocalization was analyzed by coinciding of maxima of the red and green channel by PCC. $\boldsymbol{H}, 0$ toferlin (red) and AP-2 (green) expression in immature (P5) mouse IHCs. Otoferlin and AP-2 were found to be much less expressed in immature IHCs. $\boldsymbol{I}-\boldsymbol{K}, \mathrm{AP}-2$ is not expressed in P19 hypothyroid rat cochlear IHCS $(I, J$, hypo). Expression of CtBP2 is not changed under hypothyroidism (J). Lack of staining by omitting the primary AP-2 antibody demonstrated specificity of the antibody (Fig. 2K). Cell nuclei were counterstained with DAPI. Scale bars: (in $\boldsymbol{A}-\boldsymbol{I}, \boldsymbol{K}$ ) $10 \mu \mathrm{m}$; (in J) $10 \mu \mathrm{m}$.
}

$\mathrm{kDa}$ double band in rat brain and cochlear protein lysates, corresponding to the AP-2 complex subunits $\alpha-1$ and $\alpha$-2, also known as $\alpha$-adaptin A and $\alpha$-adaptin C (Robinson, 1987, 1989; Ball et al., 1995).

Incubation of brain lysate with immobilized anti-AP-2 antibody resulted in co-IP of otoferlin (Fig. $4 A$, lane 2, co-IP). In reciprocal co-IP experiments using anti-otoferlin antibody, AP-2 polypeptides were found in both brain and cochlear lysates (Fig. $4 A$, lane 4 , co-IP, $B$, lane 3 , co-IP). These results corroborate the association of otoferlin with the AP-2 protein complex in cochlear tissue as well as mature brain, and suggest a more general role of otoferlin in CME.

CME has been shown to involve assembly of AP-2 with myosin VI (Collaco et al., 2010). Moreover, otoferlin was also shown to interact with myosin VI in IHCs (Heidrych et al., 2009). Consistent with these observations, MYO6 was found specifically coenriched in the otoferlin AC under higher stringency conditions (Fig. 1B, mouse CL-99; data not shown). Finally, analytical co-IP from rat cochlear lysates using the anti-AP-2 antibody showed coprecipitation with myosin VI (doublet band at $150 \mathrm{kDa}$; Fig. $4 C$, lane 3, co-IP) in accordance with a previously described doublet at $\sim 150 \mathrm{kDa}$ (Breckler et al., 2000). We cannot exclude that the lower band detected by the myosin VI antibody in the input is a cleavage product of myosin VI. This suggested that otoferlin, $\mathrm{AP}-2$, and myosin VI might be part of a larger protein complex.

To further characterize interaction of AP-2 and myosin VI in cochlear IHCs, we performed immunohistological staining in cochlear whole-mount preparations of adult mice (Fig. 5) using anti-AP-2 and anti-myosin VI antibodies along with highresolution deconvolution fluorescence microscopy. Labeling for myosin VI (Fig. 5A, red) and AP-2 (Fig. 5A, green) and their colocalization (Fig. $5 A$, merge) in IHCs were shown in a cochlear whole-mount preparation of an adult mouse (P19). Higher mag- 

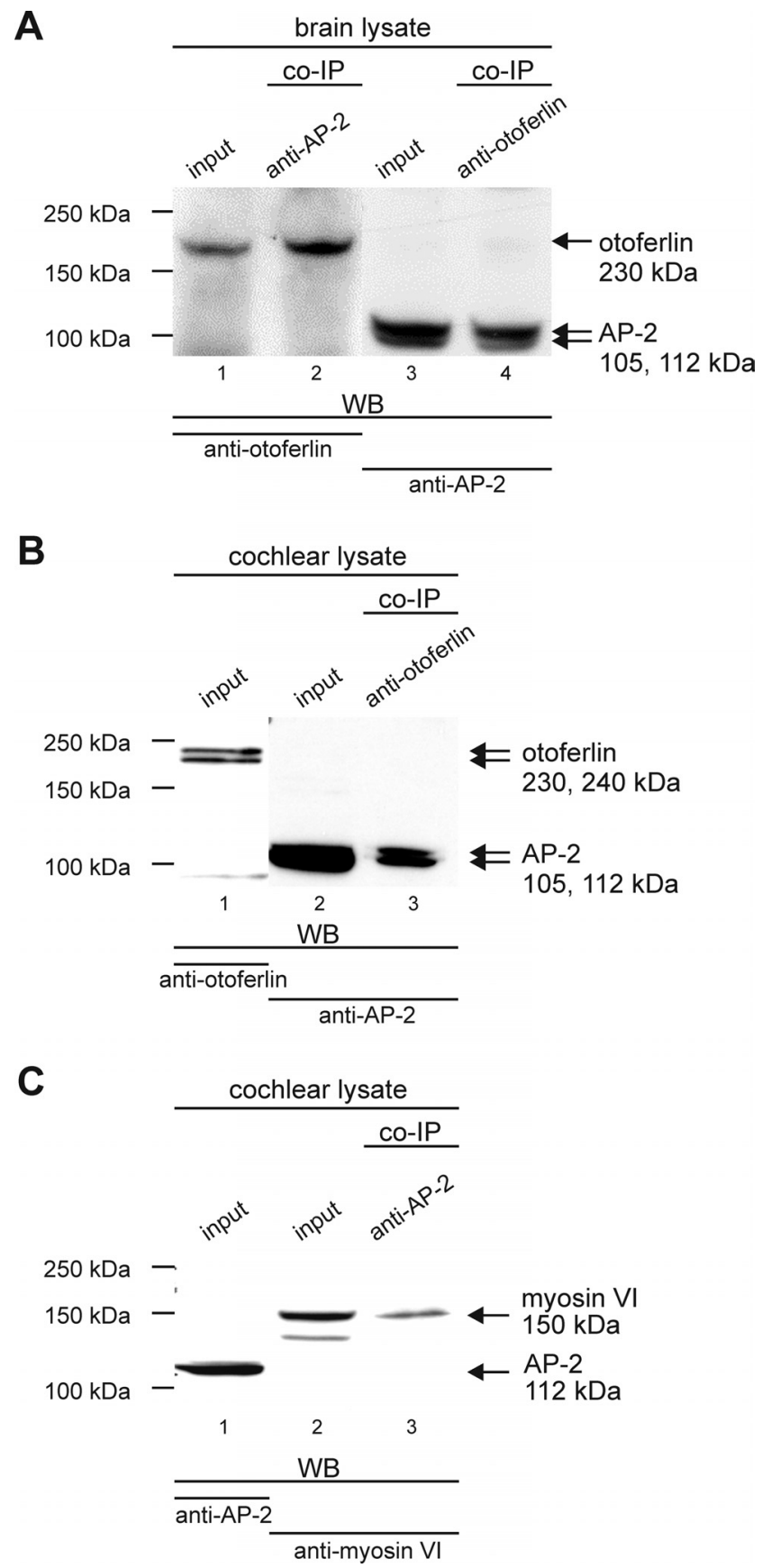

Figure 4. Analytical coimmunoprecipitation experiments in brain and cochlear lysate. $A$, Brain lysate. Lanes 1 and 3, Containing the brain lysate used for the co-IP (input), confirm the expression of otoferlin with the estimated size of $\sim 230 \mathrm{kDa}$ and the expression of AP- 2 with the estimated size of $\sim 105$ and $\sim 112 \mathrm{kDa}$ in the brain lysate, respectively (input). Lane 2, Otoferlin was coimmunoprecipitated from brain lysate by the AP-2-specific antibody. Lane 4, The otoferlin-specific antibody coimmunoprecipitated AP-2. B, Cochlear lysate. Lanes 1 and 2 (input), confirm the expression of otoferlin with the estimated size of $\sim 230$ and $\sim 240 \mathrm{kDa}$ (Schug et al., 2006) and the expression of AP-2 with the estimated size of $\sim 105$ and $\sim 112 \mathrm{kDa}$ (Ball et al., 1995) in the cochlear lysate, respectively. Lane 3, AP-2 was coimmunoprecipitated from cochlear lysate by the otoferlin-specific antibody. C, Cochlear lysate. Lanes 1 and 2 (input), Show the expression of AP- 2 with an estimated size of $\sim 112 \mathrm{kDa}$ and myosin $\mathrm{VI}$ with an estimated size of $\sim 150 \mathrm{kDa}$ in the cochlear lysate, respectively. Lane 3, Myosin VI was coimmunoprecipitated from cochlear lysate by the AP-2-specific antibody.

nification revealed that AP-2 and myosin VI were colocalized all over the IHC cytoplasm (Fig. 5B). This almost complete overlap is displayed by driving the intensity profile as described above, when cutting horizontal lines through the IHC region above the nucleus (Fig. $5 B, E$; PCC $=0.535$ ) and at the base (Fig. $5 C, F$; $P C C=0.824)$. The greatly overlapping intensity maxima display colocalization, which was found throughout the cytoplasm. The similar amount of colocalization in the apex and base of the IHC is also displayed on a vertical cut (Fig. $5 D, G$; PCC $=0.641$ ). In summary, these findings indicate a large colocalization of otoferlin with AP-2 as well as myosin VI and AP-2 in all analyzed IHC regions.

The possible involvement of clathrin-dependent endocytosis in IHCs was tested in IHCs by superfusing the drug dynasore, a noncompetitive inhibitor of dynamin GTPase activity, which triggers the fission of clathrin-coated pits via AP-2 (Macia et al., 2006; Linden, 2012) and blocks all forms of compensatory synaptic vesicle endocytosis (Newton et al., 2006). We tested whether vesicle release from either the RRP or SRP of immature and mature IHCs was limited by the relative pool refilling rates measuring $\Delta C_{\mathrm{m}}$ using repetitive stimulation (Johnson et al., 2008), which provides an indirect measurement for endocytosis. Figure 6, $A$ and $B$, show examples of $\Delta C_{\mathrm{m}}$ in mature IHCs in response to trains of $50 \mathrm{~ms}$ or $1 \mathrm{~s}$ steps to $-11 \mathrm{mV}$, which are used to investigate the depletion of the RRP and SRP, respectively. Following repeated 50 ms steps, the cumulative $\Delta C_{\mathrm{m}}$ showed a near linear increase in both control and in the presence of dynasore (Fig. $6 C$ ), indicating that the RRP is able to replenish following each step as also evident from the individual $\Delta C_{\mathrm{m}}$ (Fig. $6 E$ ). Following longlasting (1 s) voltage steps, the cumulative $\Delta C_{\mathrm{m}}$ for the SRP showed saturation that was significantly $(p<0.0001)$ more pronounced in the presence of dynasore than in control condition (Fig. 6D). The larger depletion of the SRP in IHCs in the presence of dynasore, compared with control cells, was also evident from the individual $\Delta C_{\mathrm{m}}$ (Fig. $6 F$ ). When $\Delta C_{\mathrm{m}}$ following $50 \mathrm{~ms}$ or $1 \mathrm{~s}$ steps to $-11 \mathrm{mV}$ was investigated in immature P4 to P7 IHCs, the cumulative $\Delta C_{\mathrm{m}}$ in the absence or presence of dynasore were not different, shown for individual $\Delta C_{\mathrm{m}}$ (Fig. $6 G, H$ ) or for cumulative $\Delta C_{\mathrm{m}}$ for the SRP (Fig. $6 D$, inset). These results indicate that synaptic vesicle refilling of the SRP in adult, but not immature IHCs, was significantly reduced by dynasore.

\section{Discussion}

Otoferlin, a calcium sensor for synaptic vesicle release at hair cell ribbon synapses (Yasunaga et al., 2000; Roux et al., 2006; Ramakrishnan et al., 2009), is responsible for auditory neuropathy/ dyssynchrony (Varga et al., 2003). In addition to being involved in exocytosis, we found that in mature IHCs, otoferlin interacts with AP-2, a protein complex essential for endocytic clathrincoated pit and coated-vesicle formation (Keyel et al., 2008; Rappoport, 2008; Boucrot et al., 2010). Moreover, we demonstrated that sustained exocytosis (SRP) is inhibited by the CME blocker dynasore. In IHCs, AP-2 also colocalizes and interacts with myosin VI, which also binds to clathrin-coated pits and is essential for CME (Puri, 2009; Yu et al., 2009). These findings indicate that otoferlin, by coupling exocytosis and endocytosis, could provide the basis for the indefatigable sustained exocytosis of adult IHCs (von Gersdorff and Matthews, 1994).

MS analysis from mature $(>\mathrm{P} 25)$ cochleae revealed that otoferlin is able to bind AP-2 subunits. The AP-2 adaptor complex is connected to clathrin-coated vesicles budding from the plasma membrane and consists of four distinct subunits: two subunits with the $\mathrm{Mr}$ of $\sim 100 \mathrm{kDa}$ ( $\alpha$ - and $\beta$-subunit, also known as $\alpha$ - and $\beta$-adaptin), one with the $\mathrm{Mr}$ of $\sim 50 \mathrm{kDa}$ ( $\mu$ subunit), and a small one with the $\mathrm{Mr} \sim 17 \mathrm{kDa}$ ( $\sigma$-subunit). Two isoforms of $\alpha$-adaptin (Ap2a1 and Ap2a2) encoded by two different genes have been described in mammalian cells. Whereas 
$\alpha$-adaptins are implicated in protein-protein interactions, the current consensus is that the $\beta$-subunit (Ap2b1) plays a major role in clathrin binding, while the $\mu$-subunit (Ap2m1) is involved in receptor binding and signal recognition (for reviews see, Hirst and Robinson, 1998; Pearse et al., 2000). We provided evidence that Ap2a2, Ap2b1, Ap2m1, and Ap2s1 together interact with otoferlin. This was confirmed by RT-PCR showing that Ap2a 2 and Ap2b1 are expressed in mature IHCs. Our MS analysis agrees with previous findings showing that while Ap2a2 is ubiquitously expressed, Ap2a1 is limited to neuronal tissues (Robinson, 1987, 1989).

In adult IHCs, otoferlin and AP-2 colocalize. Otoferlin and AP-2 are close to CtBP2 and the expression level of both otoferlin and AP-2 is upregulated with cochlear maturation. Increased expression of otoferlin in IHCs during maturation, confirming previous findings (Roux et al., 2006; Beurg et al., 2010), has been linked to an improved $\mathrm{Ca}^{2+}$-dependent resupply of vesicles observed after the onset of hearing (Levic et al., 2011). The resupply of vesicles is limited by the RRP or SRP refilling rates that can be determined by measuring $\Delta C_{\mathrm{m}}$ following repetitive stimulation protocols as a measure for the endocytosis capacity (Johnson et al., 2008). We show a significant reduction in sustained exocytosis when the CME blocker dynasore was used in adult IHCs, but not in immature cells. Dynasore has been shown to block all types of CME in rodent hippocampal neurons (Macia et al., 2006; Newton et al., 2006). This, together with the upregulation of AP-2 and otoferlin over development, suggests that the coupling between otoferlin and CME is likely to be a special property of IHCs around the onset of hearing. This hypothesis was further confirmed by the fact that in adult rats raised under hypothyroid conditions,

IHCs resemble an immature state, retaining low expression levels of otoferlin and AP-2 throughout their life, sustained exocytosis was impaired (Johnson et al., 2010). In the "immature" condition of hypothyroid animals, the efficient recruitment of vesicles from the larger SRP could be uncoupled from the $\mathrm{Ca}^{2+}$ dependent otoferlin-mediated vesicle resupply. Indeed, a more efficient $\mathrm{Ca}^{2+}$-dependent refilling of vesicles from internalized membrane in the apical IHC region was observed in mature IHCs (Griesinger et al., 2002, 2005). This $\mathrm{Ca}^{2+}$-dependent improvement of vesicle refilling might be the basis of the approved $\mathrm{Ca}^{2+}$ sensitivity of vesicle replenishment, which occurs with IHC maturation (Levic et al., 2011).

The additional interaction of otoferlin with myosin VI, which is involved in CME (Puri, 2009), further supports an involvement of the otoferlin-AP-2-myosin VI complex in endocytosis at the basal part and membrane internalization at the apical part of
AP-2
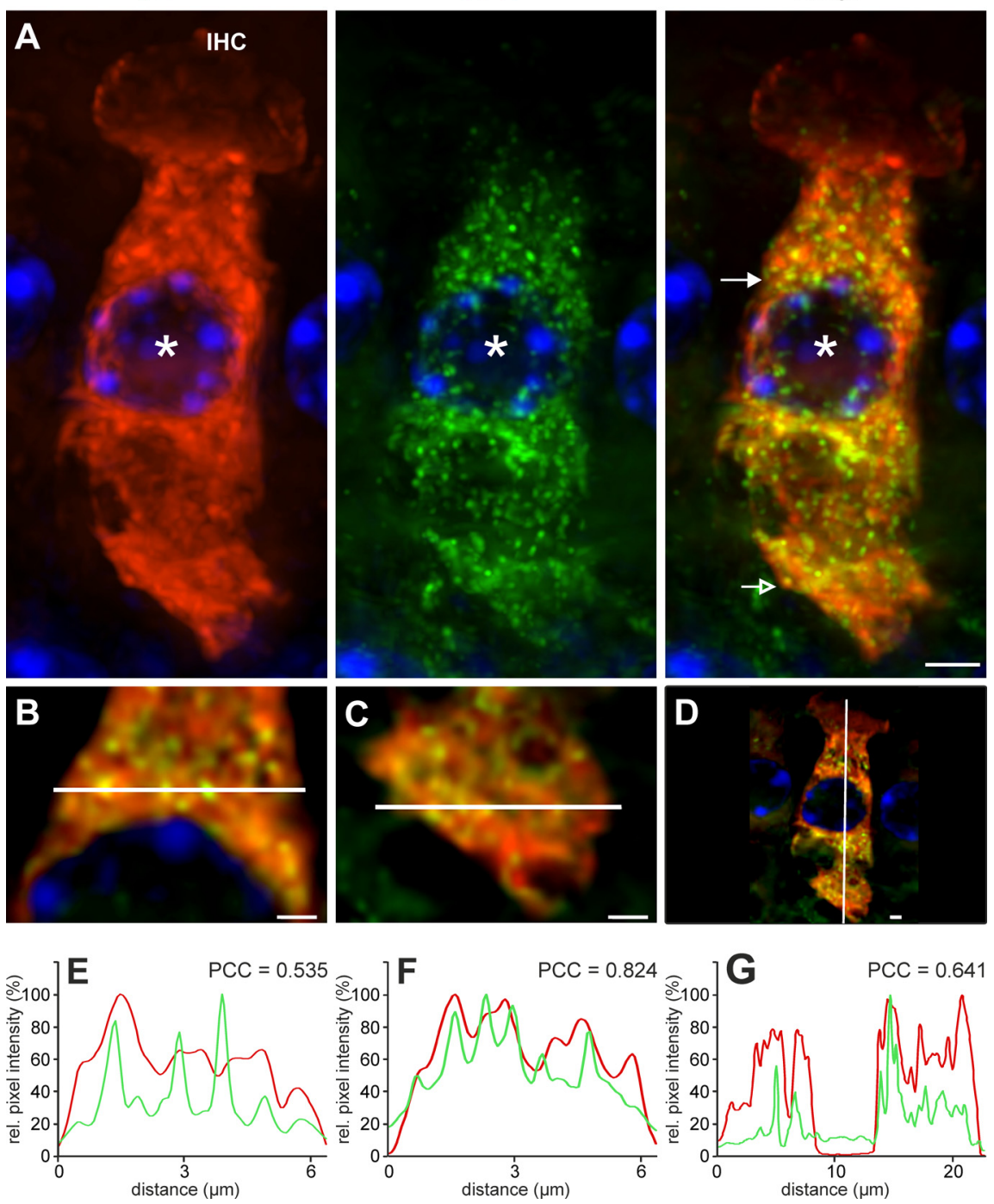

Figure 5. Colocalization of AP-2 protein and myosin VI in mature (P19) IHCs. A, Colocalization of myosin VI (red) and AP-2 green) labeling was found ubiquitously throughout the IHC except the cuticular plate. Cell nuclei were counterstained with DAPI. deconvoluted z-stack in $\boldsymbol{A}$, where $\boldsymbol{B}$ and $\boldsymbol{E}$ are derived from the supranuclear area (closed arrow in $\boldsymbol{A}$, merge), $\boldsymbol{C}$ and $\boldsymbol{F}$ from the (open arrow in $\boldsymbol{A}$, merge), and $\boldsymbol{D}$ and $\boldsymbol{G}$ from a vertical cut. Scale bars: $2 \mu \mathrm{m}$. $\boldsymbol{E}-\boldsymbol{G}$, Normalized intensity profiles are drawn from (red, Cy3; green, Alexa 488). Colocalization was analyzed by coinciding of maxima of the red and green channel by PCC. Images display maximum intensity projections of all layers of a $z$-stack.

IHCs (Griesinger et al., 2002, 2005). This agrees with previous observations showing that coated vesicles were found both at the synaptic region (IHC basal pole) and in all components of the Golgi complex located toward the apical pole of mature IHCs (Siegel and Brownell, 1986). $\mathrm{Ca}^{2+}$-dependent vesicle replenishment was described in hair cells (Moser and Beutner, 2000; Spassova et al., 2004; Cho et al., 2011; Graydon et al., 2011) and occurs with a timescale of $\sim 15-20$ s (Beutner et al., 2001; Griesinger et al., 2005). This was previously assumed to be too rapid to be achieved by a CME process that was thought to operate on a timescale of minutes (Heuser and Reese, 1973; Henkel and Almers, 1996; Granseth et al., 2006). However, this view has recently changed with an increasing number of studies showing that CME can occur within seconds rather than minutes, shown for retinal and chromaffin cells (time constant: $\tau<10$ s; (Jockusch et al., 2005; Tsai et al., 2009). 
A
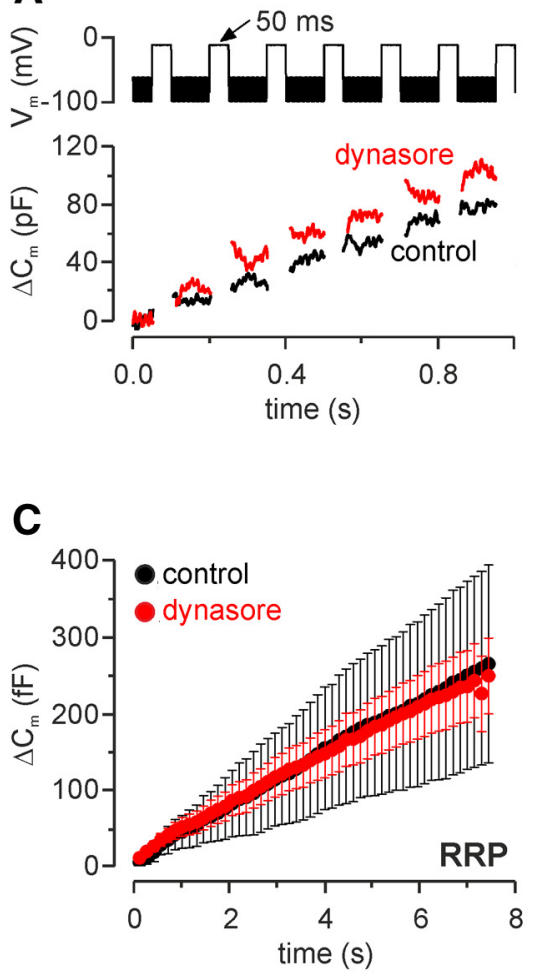

E

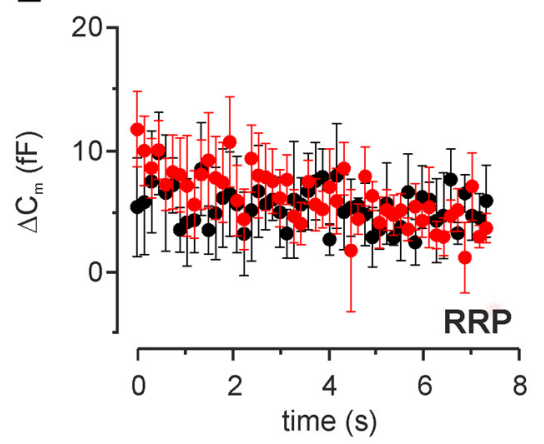

G

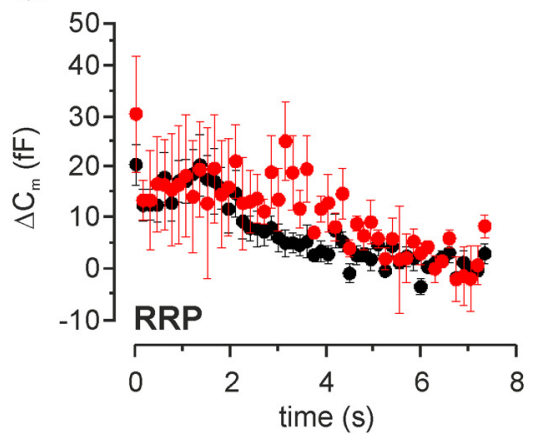

B
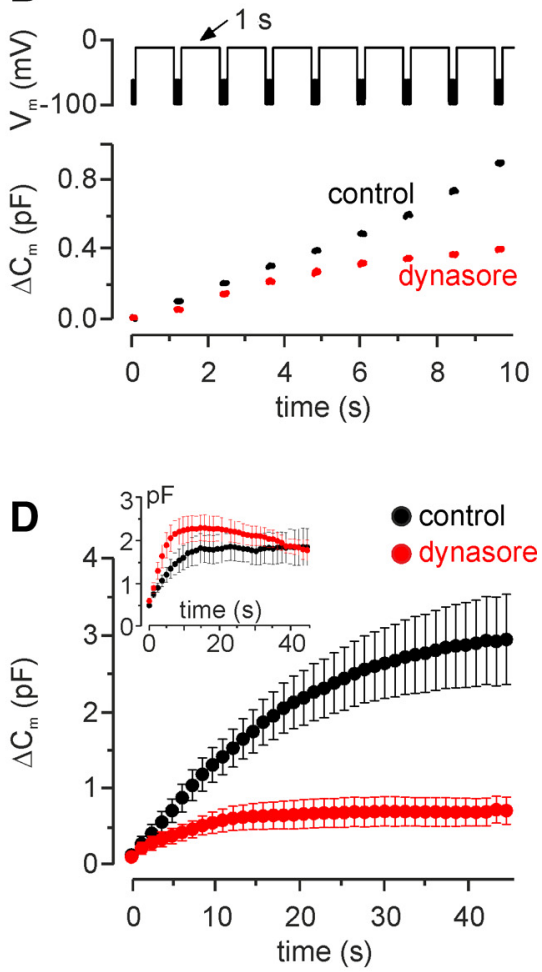

$\mathbf{F}$

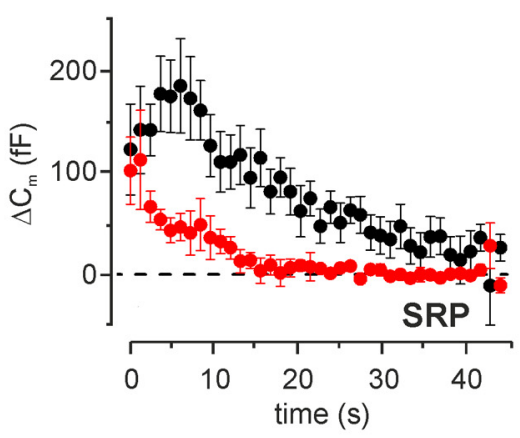

H

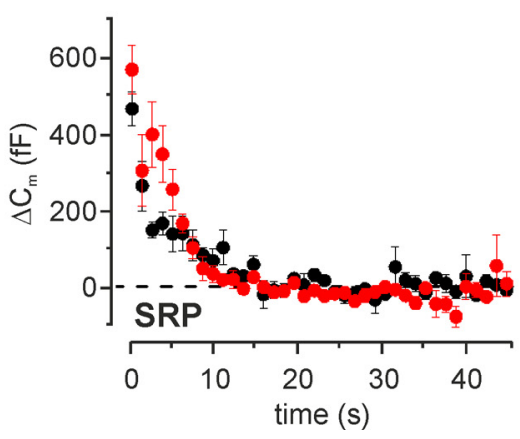

Figure 6. Effect of dynasore on vesicle pool replenishment in IHCs. $\boldsymbol{A}, \boldsymbol{B}$, Repetitive voltage steps to $-11 \mathrm{mV}$ for $50 \mathrm{~ms}$ ( $\boldsymbol{A}$, interstep interval: $100 \mathrm{~ms}$ ) or $1 \mathrm{~s}$ ( $\boldsymbol{B}$, interstep interval: $200 \mathrm{~ms}$ ) were used to elicit the RRP and SRP, respectively. For clarity, only the first few steps are shown. The top shows the respective voltage protocol used. $\boldsymbol{C}$, Average cumulative $\Delta C_{\mathrm{m}}$ values obtained in response to the $50 \mathrm{~ms}$ protocol from 3 control (P13) and 11 dynasore-treated (P11-P17) IHCs. D, Average cumulative $\Delta C_{\mathrm{m}}$ in response to the $1 \mathrm{~s}$ protocol from seven control (P13-P16) and seven dynasore-treated (P13-P17) IHCs. Inset, Cumulative $\Delta C_{m}$ from four control (P4-P7) and four dynasore-treated (P6 -P7) immature IHCs. $E$, Individual $\Delta C_{m}$ values measured for the RRP after each voltage step from IHCs shown in $\boldsymbol{C} . \boldsymbol{F}$, Individual $\Delta C_{\mathrm{m}}$ values for the SRP measured after each voltage step from IHCs shown in D. G, $\boldsymbol{H}$, Vesicle pool replenishment in immature mouse IHCs treated with dynasore. Individual $\Delta \boldsymbol{C}_{\mathrm{m}}$ values measured for the RRP in nine control (P4-P6) and three dynasore-treated (P6-P7) IHCS (G) and SRP ( $\boldsymbol{H}$; see inset in $\boldsymbol{D})$ as described in $\boldsymbol{E}$ and $\boldsymbol{F}$, respectively.

Syt1, a major $\mathrm{Ca}^{2+}$ sensor for vesicle fusion at conventional synapses (Südhof, 2002), also seems to couple both endocytosis and exocytosis (Yao et al., 2012a), and in IHCs seems to be only expressed in immature IHCs (Beurg et al., 2010; Johnson et al., 2010). Similar to otoferlin in the mature IHC (Pangršič et al., 2010), Syt1 has been suggested to affect RRP recovery but not its release (Beurg et al., 2010). The deaf pachanga mouse (Otof ${ }^{\text {Pga/Pga }}$; Schwander et al., 2007) is a mouse model of human deafness DFNB9, which carries an Otof missense mutation and causes a reduction in otoferlin protein levels in IHCs and a change in otoferlin's secondary structure. While the impaired replenishment of vesicles in the pachanga mouse was discussed to be the result of a presumptive "failure of proper priming of vesicles" for the replenishment of the RRP (Pangršič et al., 2010), a function of otoferlin in clearing exocytotic material from the release toward the perisynaptic sites of endocytosis was not excluded in the same study. It was stated that the reduced sustained exocytosis and smaller fast flush response observed in Otof ${ }^{p g a / P g a}$ IHCs might also result from a major contribution of a slowly releasable pool of vesicles to sustained exocytosis (Pangršič et al., 2010). This model suggests that there is impaired clearance of excessive vesicle membrane from the release sites in synaptotagmin mutant mice, rather than from a defect in vesicle fusion (Hosoi et al., 2009). The C2B domain of Syt1 was shown to bind the $\mu$-subunit of AP-2 (Chapman et al., 1998; Haucke et al., 2000; Poskanzer et al., 2006), thereby indicating $\mathrm{Ca}^{2+}$ dependence of vesicle fission during the CME process (Yao et al., 2012b). However, our findings imply that a CME mechanism is unlikely to be present in immature IHCs. The predominant expression of otoferlin in the plasma membrane of IHCs (Schug et al., 2006; Heidrych et al., 2008, 2009), together with its ability to interact with $\mathrm{Ca}^{2+}$ channels (Ramakrishnan et al., 2009), to bind to $\mathrm{AP}-2$ and myosin VI, and the possible presence of a CME mechanism inhibited by dynasore in mature IHCs, indicate that otoferlin likely functions to induce retrieval of vesicles from the plasma membrane, as well as to support vesicle fusion. The observation that in the brain (Roux et al., 2006; Schug et al., 2006), otoferlin can also interact with AP-2 (present study) suggests a more ubiquitous role for otoferlin in $\mathrm{Ca}^{2+}$-dependent membrane vesicle retrieval, since $\sim 90 \%$ of all clathrin-coated vesicles in neurons are involved in synaptic 
vesicle retrieval (Girard et al., 2005). So far, no members of the adaptin family have been linked to hearing deficits. However, in 20 Palestinian children with prelingual nonsyndromic hearing loss, five genomic regions were identified that may harbor novel genes for human hearing loss (Shahin et al., 2010). One of these genomic regions is localized to $17 \mathrm{p} 12-\mathrm{q} 11.2$ (DFNB85), the approximate position where the AP-2- $\beta$ (CLAPB1) large subunit has been mapped (17q11.2-q12), indicating a possible link between adaptin proteins and hearing loss.

\section{References}

Baig SM, Koschak A, Lieb A, Gebhart M, Dafinger C, Nürnberg G, Ali A, Ahmad I, Sinnegger-Brauns MJ, Brandt N, Engel J, Mangoni ME, Farooq M, Khan HU, Nürnberg P, Striessnig J, Bolz HJ (2011) Loss of $\mathrm{Ca}_{\mathrm{V}} 1.3$ (CACNA1D) function in a human channelopathy with bradycardia and congenital deafness. Nat Neurosci 14:77-84. CrossRef Medline

Ball CL, Hunt SP, Robinson MS (1995) Expression and localization of $\alpha$-adaptin isoforms. J Cell Sci 108:2865-2875. Medline

Berkefeld H, Sailer CA, Bildl W, Rohde V, Thumfart JO, Eble S, Klugbauer N, Reisinger E, Bischofberger J, Oliver D, Knaus HG, Schulte U, Fakler B (2006) $\mathrm{BK}_{\mathrm{Ca}}$-Cav channel complexes mediate rapid and localized $\mathrm{Ca}^{2+}$ activated $\mathrm{K}^{+}$signaling. Science 314:615-620. CrossRef Medline

Beurg M, Michalski N, Safieddine S, Bouleau Y, Schneggenburger R, Chapman ER, Petit C, Dulon D (2010) Control of exocytosis by synaptotagmins and otoferlin in auditory hair cells. J Neurosci 30:13281-13290. CrossRef Medline

Beutner D, Voets T, Neher E, Moser T (2001) Calcium dependence of exocytosis and endocytosis at the cochlear inner hair cell afferent synapse. Neuron 29:681-690. CrossRef Medline

Bildl W, Haupt A, Müller CS, Biniossek ML, Thumfart JO, Huber B, Fakler B, Schulte U (2012) Extending the dynamic range of label-free mass spectrometric quantification of affinity purifications. Mol Cell Proteomics 11:M111.007955. CrossRef Medline

Boucrot E, Saffarian S, Zhang R, Kirchhausen T (2010) Roles of AP-2 in clathrin-mediated endocytosis. PLoS One 5:e10597. CrossRef Medline

Breckler J, Au K, Cheng J, Hasson T, Burnside B (2000) Novel myosin VI isoform is abundantly expressed in retina. Exp Eye Res 70:121-134. CrossRef Medline

Chapman ER, Desai RC, Davis AF, Tornehl CK (1998) Delineation of the oligomerization, AP-2 binding, and synprint binding region of the $\mathrm{C} 2 \mathrm{~B}$ domain of synaptotagmin. J Biol Chem 273:32966-32972. CrossRef Medline

Cho S, Li GL, von Gersdorff H (2011) Recovery from short-term depression and facilitation is ultrafast and $\mathrm{Ca}^{2+}$ dependent at auditory hair cell synapses. J Neurosci 31:5682-5692. CrossRef Medline

Collaco A, Jakab R, Hegan P, Mooseker M, Ameen N (2010) $\alpha$-AP-2 directs myosin VI-dependent endocytosis of cystic fibrosis transmembrane conductance regulator chloride channels in the intestine. J Biol Chem 285: 17177-17187. CrossRef Medline

Engel J, Braig C, Rüttiger L, Kuhn S, Zimmermann U, Blin N, Sausbier M, Kalbacher H, Münkner S, Rohbock K, Ruth P, Winter H, Knipper M (2006) Two classes of outer hair cells along the tonotopic axis of the cochlea. Neuroscience 143:837-849. CrossRef Medline

Friauf E, Wenz M, Oberhofer M, Nothwang HG, Balakrishnan V, Knipper M, Löhrke S (2008) Hypothyroidism impairs chloride homeostasis and onset of inhibitory neurotransmission in developing auditory brainstem and hippocampal neurons. Eur J Neurosci 28:2371-2380. CrossRef Medline

Girard M, Allaire PD, McPherson PS, Blondeau F (2005) Nonstoichiometric relationship between clathrin heavy and light chains revealed by quantitative comparative proteomics of clathrin-coated vesicles from brain and liver. Mol Cell Proteomics 4:1145-1154. CrossRef Medline

Granseth B, Odermatt B, Royle SJ, Lagnado L (2006) Clathrin-mediated endocytosis is the dominant mechanism of vesicle retrieval at hippocampal synapses. Neuron 51:773-786. CrossRef Medline

Graydon CW, Cho S, Li GL, Kachar B, von Gersdorff H (2011) Sharp Ca ${ }^{2+}$ nanodomains beneath the ribbon promote highly synchronous multivesicular release at hair cell synapses. J Neurosci 31:16637-16650. CrossRef Medline

Griesinger CB, Richards CD, Ashmore JF (2002) Fml-43 reveals mem- brane recycling in adult inner hair cells of the mammalian cochlea. J Neurosci 22:3939-3952. Medline

Griesinger CB, Richards CD, Ashmore JF (2005) Fast vesicle replenishment allows indefatigable signalling at the first auditory synapse. Nature 435: 212-215. CrossRef Medline

Haucke V, Wenk MR, Chapman ER, Farsad K, De Camilli P (2000) Dual interaction of synaptotagmin with $\mu 2$ - and $\alpha$-adaptin facilitates clathrincoated pit nucleation. EMBO J 19:6011-6019. CrossRef Medline

Heidrych P, Zimmermann U, Bress A, Pusch CM, Ruth P, Pfister M, Knipper M, Blin N (2008) Rab8b GTPase, a protein transport regulator, is an interacting partner of otoferlin, defective in a human autosomal recessive deafness form. Hum Mol Genet 17:3814-3821. CrossRef Medline

Heidrych P, Zimmermann U, Kuhn S, Franz C, Engel J, Duncker SV, Hirt B, Pusch CM, Ruth P, Pfister M, Marcotti W, Blin N, Knipper M (2009) Otoferlin interacts with myosin VI: implications for maintenance of the basolateral synaptic structure of the inner hair cell. Hum Mol Genet 18: 2779-2790. CrossRef Medline

Henkel AW, Almers W (1996) Fast steps in exocytosis and endocytosis studied by capacitance measurements in endocrine cells. Curr Opin Neurobiol 6:350-357. CrossRef Medline

Heuser JE, Reese TS (1973) Evidence for recycling of synaptic vesicle membrane during transmitter release at the frog neuromuscular junction. J Cell Biol 57:315-344. Medline

Hirst J, Robinson MS (1998) Clathrin and adaptors. Biochim Biophys Acta 1404:173-193. CrossRef Medline

Hosoi N, Holt M, Sakaba T (2009) Calcium dependence of exo- and endocytotic coupling at a glutamatergic synapse. Neuron 63:216-229. CrossRef Medline

Hua Y, Sinha R, Thiel CS, Schmidt R, Hüve J, Martens H, Hell SW, Egner A, Klingauf J (2011) A readily retrievable pool of synaptic vesicles. Nat Neurosci 14:833-839. CrossRef Medline

Jockusch WJ, Praefcke GJ, McMahon HT, Lagnado L (2005) Clathrindependent and clathrin-independent retrieval of synaptic vesicles in retinal bipolar cells. Neuron 46:869-878. CrossRef Medline

Johnson CP, Chapman ER (2010) Otoferlin is a calcium sensor that directly regulates SNARE-mediated membrane fusion. J Cell Biol 191:187-197. CrossRef Medline

Johnson SL, Marcotti W, Kros CJ (2005) Increase in efficiency and reduction in $\mathrm{Ca}^{2}+$ dependence of exocytosis during development of mouse inner hair cells. J Physiol 563:177-191. Medline

Johnson SL, Forge A, Knipper M, Münkner S, Marcotti W (2008) Tonotopic variation in the calcium dependence of neurotransmitter release and vesicle pool replenishment at mammalian auditory ribbon synapses. J Neurosci 28:7670-7678. CrossRef Medline

Johnson SL, Franz C, Knipper M, Marcotti W (2009) Functional maturation of the exocytotic machinery at gerbil hair cell ribbon synapses. J Physiol 587:1715-1726. CrossRef Medline

Johnson SL, Franz C, Kuhn S, Furness DN, Rüttiger L, Münkner S, Rivolta MN, Seward EP, Herschman HR, Engel J, Knipper M, Marcotti W (2010) Synaptotagmin IV determines the linear $\mathrm{Ca}^{2+}$ dependence of vesicle fusion at auditory ribbon synapses. Nat Neurosci 13:45-52. CrossRef Medline

Keyel PA, Thieman JR, Roth R, Erkan E, Everett ET, Watkins SC, Heuser JE, Traub LM (2008) The AP-2 adaptor $\beta 2$ appendage scaffolds alternate cargo endocytosis. Mol Biol Cell 19:5309-5326. CrossRef Medline

Knipper M, Zinn C, Maier H, Praetorius M, Rohbock K, Köpschall I, Zimmermann U (2000) Thyroid hormone deficiency before the onset of hearing causes irreversible damage to peripheral and central auditory systems. J Neurophysiol 83:3101-3112. Medline

Knirsch M, Brandt N, Braig C, Kuhn S, Hirt B, Münkner S, Knipper M, Engel $\mathrm{J}$ (2007) Persistence of $\mathrm{Ca}_{\mathrm{V}} 1.3 \mathrm{Ca}^{2+}$ channels in mature outer hair cells supports outer hair cell afferent signaling. J Neurosci 27:6442-6451. CrossRef Medline

Levic S, Bouleau Y, Dulon D (2011) Developmental acquisition of a rapid calcium-regulated vesicle supply allows sustained high rates of exocytosis in auditory hair cells. PLoS One 6:e25714. CrossRef Medline

Linden DJ (2012) A late phase of LTD in cultured cerebellar Purkinje cells requires persistent dynamin-mediated endocytosis. J Neurophysiol 107: 448-454. CrossRef Medline

Macia E, Ehrlich M, Massol R, Boucrot E, Brunner C, Kirchhausen T (2006) Dynasore, a cell-permeable inhibitor of dynamin. Dev Cell 10:839-850. CrossRef Medline 
Mirghomizadeh F, Pfister M, Apaydin F, Petit C, Kupka S, Pusch CM, Zenner HP, Blin N (2002) Substitutions in the conserved C2C domain of otoferlin cause DFNB9, a form of nonsyndromic autosomal recessive deafness. Neurobiol Dis 10:157-164. CrossRef Medline

Moser T, Beutner D (2000) Kinetics of exocytosis and endocytosis at the cochlear inner hair cell afferent synapse of the mouse. Proc Natl Acad Sci U S A 97:883-888. CrossRef Medline

Müller CS, Haupt A, Bildl W, Schindler J, Knaus HG, Meissner M, Rammner B, Striessnig J, Flockerzi V, Fakler B, Schulte U (2010) Quantitative proteomics of the $\mathrm{Ca}_{\mathrm{V}} 2$ channel nano-environments in the mammalian brain. Proc Natl Acad Sci U S A 107:14950-14957. CrossRef Medline

Newton AJ, Kirchhausen T, Murthy VN (2006) Inhibition of dynamin completely blocks compensatory synaptic vesicle endocytosis. Proc Natl Acad Sci U S A 103:17955-17960. CrossRef Medline

Pandey A, Andersen JS, Mann M (2000) Use of mass spectrometry to study signaling pathways. Sci STKE 2000:pl1. Medline

Pangršič T, Lasarow L, Reuter K, Takago H, Schwander M, Riedel D, Frank T, Tarantino LM, Bailey JS, Strenzke N, Brose N, Müller U, Reisinger E, Moser T (2010) Hearing requires otoferlin-dependent efficient replenishment of synaptic vesicles in hair cells. Nat Neurosci 13:869-876. CrossRef Medline

Pangršič T, Reisinger E, Moser T (2012) Otoferlin: a multi- $\mathrm{C}_{2}$ domain protein essential for hearing. Trends Neurosci 35:671-680. CrossRef Medline

Pearse BM, Smith CJ, Owen DJ (2000) Clathrin coat construction in endocytosis. Curr Opin Struct Biol 10:220-228. CrossRef Medline

Poskanzer KE, Fetter RD, Davis GW (2006) Discrete residues in the C2B domain of synaptotagmin I independently specify endocytic rate and synaptic vesicle size. Neuron 50:49-62. CrossRef Medline

Puri C (2009) Loss of myosin VI no insert isoform (NoI) induces a defect in clathrin-mediated endocytosis and leads to caveolar endocytosis of transferrin receptor. J Biol Chem 284:34998-35014. CrossRef Medline

Ramakrishnan NA, Drescher MJ, Drescher DG (2009) Direct Interaction of Otoferlin with Syntaxin 1A, SNAP-25, and the L-type voltage-gated calcium channel $\mathrm{Ca}_{\mathrm{V}} 1.3$. J Biol Chem 284:1364-1372. Medline

Rappoport JZ (2008) Focusing on clathrin-mediated endocytosis. Biochem J 412:415-423. CrossRef Medline

Robinson MS (1987) 100-kD coated vesicle proteins: molecular heterogeneity and intracellular distribution studied with monoclonal antibodies. J Cell Biol 104:887-895. CrossRef Medline

Robinson MS (1989) Cloning of cDNAs encoding two related 100-kD coated vesicle proteins ( $\alpha$-adaptins). J Cell Biol 108:833-842. CrossRef Medline

Roux I, Safieddine S, Nouvian R, Grati M, Simmler MC, Bahloul A, Perfettini I, Le Gall M, Rostaing P, Hamard G, Triller A, Avan P, Moser T, Petit C (2006) Otoferlin, defective in a human deafness form, is essential for exocytosis at the auditory ribbon synapse. Cell 127:277-289. CrossRef Medline

Schnee ME, Santos-Sacchi J, Castellano-Muñoz M, Kong JH, Ricci AJ (2011) Calcium-dependent synaptic vesicle trafficking underlies indefatigable release at the hair cell afferent fiber synapse. Neuron 70:326-338. CrossRef Medline

Schug N, Braig C, Zimmermann U, Engel J, Winter H, Ruth P, Blin N, Pfister M, Kalbacher H, Knipper M (2006) Differential expression of otoferlin in brain, vestibular system, immature and mature cochlea of the rat. Eur J Neurosci 24:3372-3380. CrossRef Medline

Schwander M, Sczaniecka A, Grillet N, Bailey JS, Avenarius M, Najmabadi H, Steffy BM, Federe GC, Lagler EA, Banan R, Hice R, Grabowski-Boase L, Keithley EM, Ryan AF, Housley GD, Wiltshire T, Smith RJ, Tarantino
LM, Müller U (2007) A forward genetics screen in mice identifies recessive deafness traits and reveals that pejvakin is essential for outer hair cell function. J Neurosci 27:2163-2175. CrossRef Medline

Shahin H, Walsh T, Rayyan AA, Lee MK, Higgins J, Dickel D, Lewis K, Thompson J, Baker C, Nord AS, Stray S, Gurwitz D, Avraham KB, King MC, Kanaan M (2010) Five novel loci for inherited hearing loss mapped by SNP-based homozygosity profiles in Palestinian families. Eur J Hum Genet 18:407-413. CrossRef Medline

Sharif-Naeini R, Folgering JH, Bichet D, Duprat F, Lauritzen I, Arhatte M, Jodar M, Dedman A, Chatelain FC, Schulte U, Retailleau K, Loufrani L, Patel A, Sachs F, Delmas P, Peters DJ, Honor é E (2009) Polycystin-1 and -2 dosage regulates pressure sensing. Cell 139:587-596. CrossRef Medline

Siegel JH, Brownell WE (1986) Synaptic and Golgi membrane recycling in cochlear hair cells. J Neurocytol 15:311-328. CrossRef Medline

Spassova MA, Avissar M, Furman AC, Crumling MA, Saunders JC, Parsons TD (2004) Evidence that rapid vesicle replenishment of the synaptic ribbon mediates recovery from short-term adaptation at the hair cell afferent synapse. J Assoc Res Otolaryngol 5:376-390. CrossRef Medline

Stefanini M, De Martino C, Zamboni L (1967) Fixation of ejaculated spermatozoa for electron microscopy. Nature 216:173-174. CrossRef Medline

Südhof TC (2002) Synaptotagmins: why so many? J Biol Chem 277:7629_ 7632. CrossRef Medline

Tsai CC, Lin CL, Wang TL, Chou AC, Chou MY, Lee CH, Peng IW, Liao JH, Chen YT, Pan CY (2009) Dynasore inhibits rapid endocytosis in bovine chromaffin cells. Am J Physiol Cell Physiol 297:C397-406. CrossRef Medline

Uziel A, Legrand C, Ohresser M, Marot M (1983) Maturational and degenerative processes in the organ of Corti after neonatal hypothyroidism. Hear Res 11:203-218. CrossRef Medline

Varga R, Kelley PM, Keats BJ, Starr A, Leal SM, Cohn E, Kimberling WJ (2003) Non-syndromic recessive auditory neuropathy is the result of mutations in the otoferlin (OTOF) gene. J Med Genet 40:45-50. CrossRef Medline

von Gersdorff H, Matthews G (1994) Dynamics of synaptic vesicle fusion and membrane retrieval in synaptic terminals. Nature 367:735-739. CrossRef Medline

Yao J, Kwon SE, Gaffaney JD, Dunning FM, Chapman ER (2012a) Uncoupling the roles of synaptotagmin I during endo- and exocytosis of synaptic vesicles. Nat Neurosci 15:243-249. Medline

Yao LH, Rao Y, Varga K, Wang CY, Xiao P, Lindau M, Gong LW (2012b) Synaptotagmin 1 is necessary for the $\mathrm{Ca}^{2+}$ dependence of clathrinmediated endocytosis. J Neurosci 32:3778-3785. CrossRef Medline

Yasunaga S, Grati M, Cohen-Salmon M, El-Amraoui A, Mustapha M, Salem N, El-Zir E, Loiselet J, Petit C (1999) A mutation in OTOF, encoding otoferlin, a FER-1-like protein, causes DFNB9, a nonsyndromic form of deafness. Nat Genet 21:363-369. CrossRef Medline

Yasunaga S, Grati M, Chardenoux S, Smith TN, Friedman TB, Lalwani AK, Wilcox ER, Petit C (2000) OTOF encodes multiple long and short isoforms: genetic evidence that the long ones underlie recessive deafness DFNB9. Am J Hum Genet 67:591-600. CrossRef Medline

Yu C, Feng W, Wei Z, Miyanoiri Y, Wen W, Zhao Y, Zhang M (2009) Myosin VI undergoes cargo-mediated dimerization. Cell 138:537-548. CrossRef Medline

Zampini V, Johnson SL, Franz C, Lawrence ND, Münkner S, Engel J, Knipper M, Magistretti J, Masetto S, Marcotti W (2010) Elementary properties of $\mathrm{Ca}_{\mathrm{V}} 1.3 \mathrm{Ca}^{2+}$ channels expressed in mouse cochlear inner hair cells. J Physiol 588:187-199. CrossRef Medline 